\title{
Technical Options and Cost Estimates for Spent Nuclear Fuel Management at the Barakah Nuclear Power Plants
}

\author{
Shadwan M. M. Esmail $(\mathbb{D}$ and Jae Hak Cheong $\mathbb{D}$ \\ Department of Nuclear Engineering, Kyung Hee University, 1732, Deogyeong-daero, Giheung-gu, Yongin-si, \\ Gyeonggi-do 17104, Republic of Korea \\ Correspondence should be addressed to Jae Hak Cheong; jhcheong@khu.ac.kr
}

Received 26 August 2021; Accepted 30 October 2021; Published 12 November 2021

Academic Editor: Raffaella Testoni

Copyright (C) 2021 Shadwan M. M. Esmail and Jae Hak Cheong. This is an open access article distributed under the Creative Commons Attribution License, which permits unrestricted use, distribution, and reproduction in any medium, provided the original work is properly cited.

\begin{abstract}
In the planning and management of the interim storage of spent nuclear fuel, the technical and economic parameters that are involved have a significant role in increasing the efficiency of the storage system. Optimal parameters will reduce the total economic costs for countries embarking on nuclear energy, such as the UAE. This study evaluated the design performance and economic feasibility of various structures and schedules, to determine an optimal combination of parameters for the management of spent nuclear fuel. With the introduction of various storage technology arrangements and expected costs per unit for the storage system design, we evaluated eight major scenarios, each with a cost analysis based on technological and economic issues. We executed a number of calculations based on the use of these storage technologies, and considered their investment costs. These calculations, which were aligned with the net present value approach and conducted using MS Project and MATLAB software programs, considered the capacities of the spent fuel pools and the amount of spent nuclear fuel (SNF) that will be transferred to dry storage facilities. As soon as they sufficiently cool, the spent nuclear fuel is to be stored in a pool storage facility. The results show that applying a centralized dry storage (CDS) system strategy is not an economically feasible solution, compared with using a permanent disposal facility (PDF) (unless the variable investment cost is reduced or changed). The optimal strategy involves operating a spent fuel pool island (SFPI) storage after the first 20 years of the start of the permanent shutdown of the reactor. After 20 years, the spent fuel is then transferred to a PDF. This strategy also results in a $20.9 \%$ to $26.1 \%$ reduction in the total cost compared with those of the other strategies. The total cost of the proposed strategy is approximately 4,307 million USD. The duration of the fuel storage and the investment cost, particularly the variable investment cost, directly affect the choice of facility storage.
\end{abstract}

\section{Introduction}

Countries in the Arabian Peninsula are highly motivated to progress faster toward the realization of nuclear power plant (NPP) technology programs. This is especially true for Saudi Arabia (SA) and the United Arab Emirates (UAE). Recently, the UAE officially announced the successful operation of the first unit of its Barakah power plants (PPs), which have an installed capacity of $1.4 \mathrm{GWe}$ per unit, or a total of $5.6 \mathrm{GWe}$ once all intended PPs are fully operational. These power plants are expected to deliver $25 \%$ of the electricity of the UAE, to prevent the release of over 21 million tons of carbon emissions every year [1]. Construction of the Barakah PPs began in 2012, with a total cost of 22.4 billion USD, whereas construction of Barakah unit 1 was completed in 2018. The Federal Authority for Nuclear Regulation (FANR) of the UAE then issued a 60-year operating license to Nawah Energy Company in February 2020. The fuel loading process was completed in early March 2020, and the PP started its commercial operations in August 2020. Meanwhile, the construction of unit 2 was completed earlier in July, whereas Barakah units 3 and 4 are approximately 92\% and 85\% complete, respectively, and are undergoing testing. Overall, the construction of the Barakah plant is estimated to be approximately $94 \%$ complete [2, 3].

One of the most important and challenging problems that should be addressed after the operation of a commercial nuclear power plant is the safe management of nuclear fuel, 
with a duration that should be accounted for in the decommissioning of an NPP. Specifically, in this duration, the spent nuclear fuel (SNF) will release large quantities of radiation and decay heat. The current practice is to store SNF from power reactors in water-filled pools near the reactors to allow the heat and radiation levels of the SNF to decrease [4]. Safe management of SNF during plant operations and during the decommissioning process must focus on protecting workers, the public, and the environment from radiation exposure. Therefore, it is important to discuss and investigate SNF workable management options, in particular, in terms of technical and economic factors. The transportation of SNF from a spent fuel pool (SFP) to an interim storage can cause delays during the decommissioning process because of a number of activities that have to be conducted during this process, which may contribute to further delays. In addition, it is essential to estimate the total cost of implementing this process.

Experts have developed a number of economic models to improve the management of the interim storage system strategy. Each model involves a unique set of technical and economic factors that make them easily understandable, more efficient, and more accurate. The perspectives of these models may vary among case studies. Most of these models have been implemented in the estimation of the costs of the SNF waste of a new nuclear power plant. These models, which have been implemented in different countries, can be classified based on the material flow calculation method, following probabilistic approach, cost calculation method, and country of application, as shown in Figure 1 [5-31]. Depending on these particularities, a number of the models also consider a more specific context to obtain more accurate results for a specific country. Technological options can be adjusted to better match the needs of a country, as seen in France, the US, Spain, South Korea, and China $[7,9,24,31-37]$.

In this study, we developed a model that uses the value of all future cash flows over the entire life of an investment discounted to the present, i.e., the net present value (NPV), and the on-off operation switching mode for each facility. To develop the model, we used the MATLAB software, which is able to show the variation in cost over time, and also provide an accurate final cost estimation for nuclear fuel cycle waste management $[7,25,26,38]$.

As of the time of this writing, the UAE has started running Barakah unit 1, whereas units 2, 3, and 4 are expected to be in commission within the next two or four years. However, because a national repository site for the SNF has not yet been determined, the UAE government plans to allocate suitable facilities for these SNFs. Currently, in accordance to international safety standards recommendations for NPP spent fuel management, short-term fuel storage is recommended. In addition, the removed SNF should be managed appropriately and efficiently until its disposal in a final repository. However, the UAE has not yet published a specific or clear strategic nuclear-power development plan for managing SNFs [1-3]. The UAE also lacks practical experience in implementing such an official plan for handling future accumulated SNFs [39].
1.1. Site Status and Decommissioning Process of Barakah Site. The Barakah site comprises four units of the APR-1400 reactor (Barakah-1, Barakah-2, Barakah-3, and Barakah-4) with a total capacity of 5.6 GWe. Barakah-1 has already started successful operation, whereas the others will join the service within a few years. However, regardless of their starting dates, all units should undergo the same procedures for safe decommissioning. Each unit on the Barakah site will expire after a lifetime of 60 years. Therefore, we expect Barakah-1 to decommission earlier than the other units because it started its operations earlier. The designed expiration dates of the Barakah site reactor units are outlined in Table 1. This study establishes the management of spent fuel in decommissioning Barakah reactors 1, 2, 3, and 4 [40].

There are several theoretical spent fuel management plans that can be implemented based on several considerations that directly affect the selection of the plan [40-44]. We consider these parameters in this work, as follows:

\section{Site conditions of Barakah and decommissioning process}

Current status of nuclear fuel and SNFs generation and transportation prospect

Major costs and unit costs for spent fuel management options of the Barakah site

We also assumed that the decommissioning plan for Barakah-1 will be divided into four stages, with a total duration of approximately 15 years, as shown in Figure 2, as follows:

Preplanning: approximately two years

Transition period: minimum of five years

Decommissioning and dismantling: minimum of six years

Site restoration and release: minimum of two years [41]

In this study, we considered the durations for these decommissioning stages, i.e., transition, decontamination and decommissioning (D\&D), and site remediation, which were established by Korea Hydro \& Nuclear Power (KHNP) for upcoming shutdowns in nearby units. However, the decommissioning schedules may change because of the application of fuel management for each unit of the Barakah site, thus shifting the time of the decommissioning process for each reactor $[42,43]$. In addition, at the end of the cooling period (i.e., after the permanent shutdown), four main practical strategies for NPP decommissioning can be applied as workable options for managing spent fuel at the Barakah site, specifically SFP, SFP island (SFPI), independent spent fuel storage installation (ISFSI), and transshipment to neighboring plants or centralized dry or permanent disposal facilities (PDF), based on the International Atomic Energy Agency (IAEA) classification for storage and disposal facilities [36]. However, in the case of transshipments, the plant that receives the spent fuel may again use the SFPI or ISFSI strategy. The SNF will be transported to a centralized dry storage, and, after the construction of a high-level repository, will be finally transported to that repository, as shown in Figures 3 and 4. 

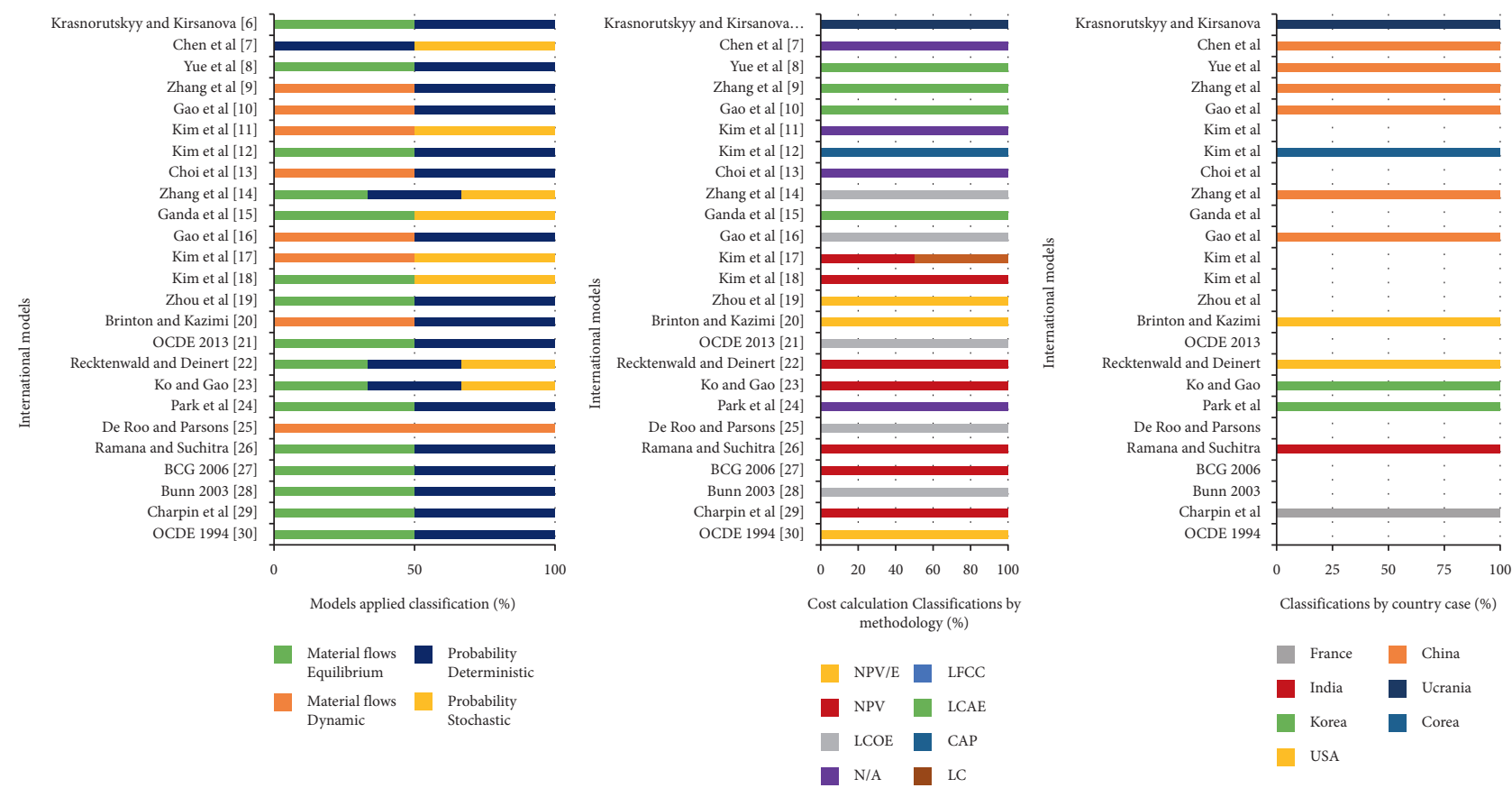

FIGURE 1: Summary classifications of international models applied, in percentages.

TABLE 1: Overview of Barakah site reactors and expected shutdown dates [40].

\begin{tabular}{lccccc}
\hline NPP & Gross capacity (MWe) & Reactor type & Construction start date & Commercial operation & Year of shutdown \\
\hline Barakah-1 & 1400 & PWR & $07-2012$ & $08-2020$ & $08-2080$ \\
Barakah-2 & 1400 & PWR & $04-2013$ & $06-2022^{*}$ & $06-2082^{*}$ \\
Barakah-3 & 1400 & PWR & $09-2014$ & $10-2023^{*}$ & $10-2083^{*}$ \\
Barakah-4 & 1400 & PWR & $07-2015$ & $04-2024^{*}$ & $04-2084^{*}$ \\
\hline
\end{tabular}

*Expectation.

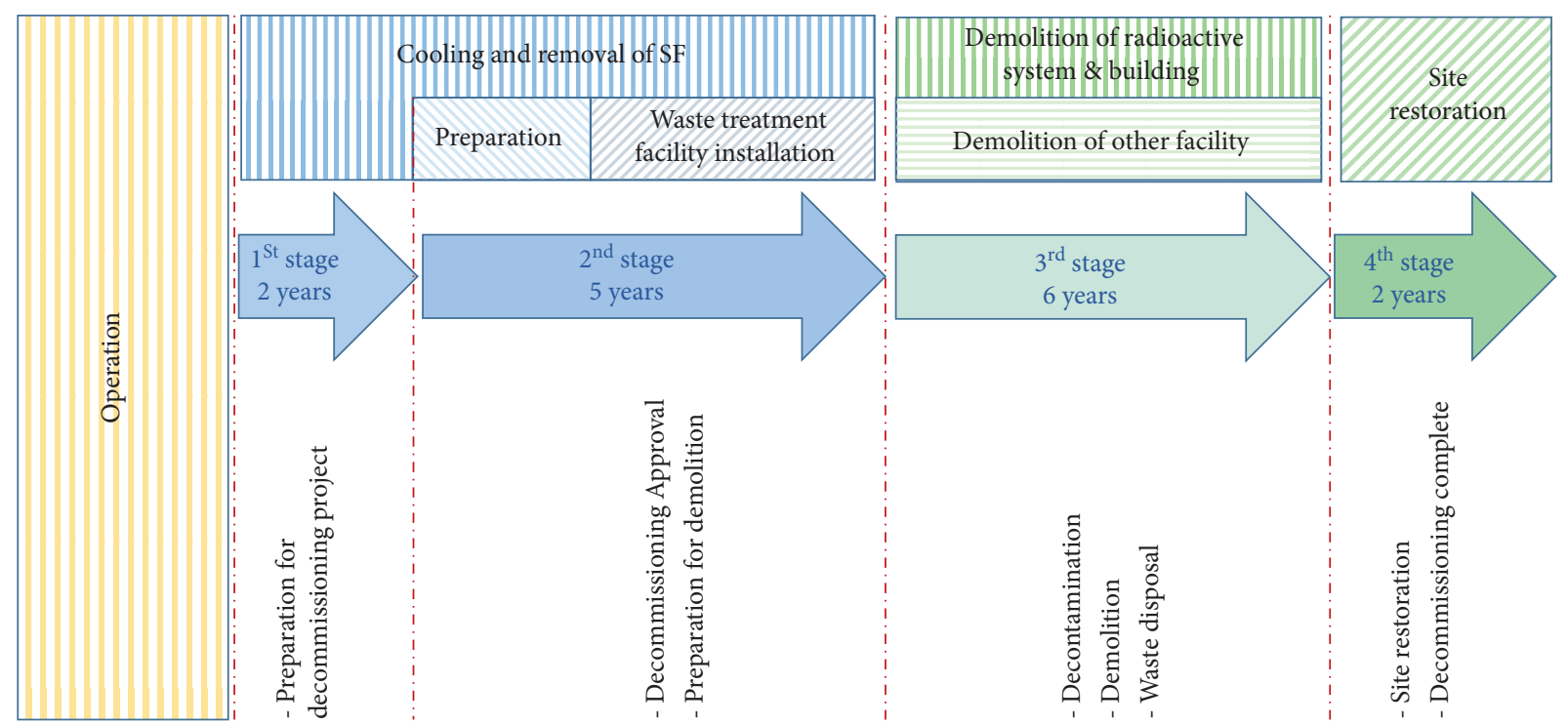

FIgURE 2: Barakah site decommissioning stages. 
1.2. UAE National Policy and National Program for Spent Fuel Management. The UAE has adapted many lessons learned from industries and previous practices, one of which is the South Korean experience with its Spent Fuel Management Program (SFMP), which, in the UAE, can be summarized as the direct disposal of spent fuel together with intermediatelevel radioactive waste (ILW) in a geological disposal facility (GDF), which will become operational 80 years after the start of the commercial operation of the NPPs. On the other hand, in the design of the Barakah NPPs, the storage pool for spent fuel has been increased in size to a capacity of up to 20 years of spent fuel in the wet pools [39].

For comparison, the US has considered two options for a long-term approach to SNF management during NPP decommissioning:

Wet storage, wherein the SNFs continue to be stored in an SFP pool or SFPI

Dry storage, wherein the SNFs are stored in an ISFSI

These two options have been further evaluated through a comparison of their long-term costs. Based on this analysis, the ISFSI option is more justified in terms of cost-benefit tradeoff, making it a preferable option for ensuring that the fuel is placed in a safer configuration for long-term storage $[37,46]$. By contrast, in the case of a number of other countries, such as Spain, the SNFs will be stored in pools for several years, after which they will be stored in casks and transferred directly to a centralized interim storage (CIS), e.g., a centralized dry storage (CDS) or a deep geological repository (DGR), e.g., a $\operatorname{PDF}[35,36]$.

To properly evaluate the workable SNF management options and the expenditures needed to implement these kinds of solutions, it is necessary to know the currently available SNF management technologies that use these approaches, i.e., on-site SNF storage administration methods, such as concrete casks, metal casks, and dualpurpose casks (DPC); wet storage methods, such as SFP or SFPI; and dry storage methods, such as ISFSI. In addition, in accordance with IAEA safety considerations, it is necessary to estimate the amount of SNF to be removed from each NPP during the transition from operation to decommissioning of the NPP facility [46-48]. It is also important to understand the concept of SFPI, which is used to manage and isolate the SNF from the SFP, while maintaining the temperature of the SFP within allowable limits. The process of estimating the amount of SNF will be explained in further detail in Section 2.2.

An SFP is a storage pool located at a reactor site and is used to cool the SNF. This storage pool can be expanded depending on the site conditions. On the other hand, an SFPI comprises several subsystems that support other systems from the existing plant to enable decommissioning activities without removing the SNF from the storage pool $[47,48]$. To set up an SFPI, an existing SFP is modified via the addition and installation of independent components for cooling, clean up, monitoring, control, and electrical power. As soon as the adaptation is completed, the removed SNFs are stored in the SFP or SFPI storage facility. Once an ISFSI is built, the SNFs are transferred to the ISFSI from the SFP or SFPI storage facility, which continues to be in operation until the transfer of SNFs to the ISFSI is completed [48]. Subsequently, the decommissioning of the SFP or SFPI begins. The use of SFP, SFPI, and ISFSI technologies has proved to be successful, as demonstrated in other countries such as the US, and can therefore be further applied to the Barakah site [46-51].

For comparison, the timeline for the interim storage facilities of the Shin-Kori nuclear power plant in South Korea will start by 2093. By contrast, in this study, we assumed different timelines for the interim storage facilities, which could start operation approximately 20 years after the first reactor begins to shut down. These timelines are based on expected facility operating lifetimes of $20,30,40,50$, or 60 years for SFPI, ISFSI, CDS, and PDF, respectively [51-53]. In the Barakah site, the first of the four NPPs will shut down by 2080. It is inevitable to store some of the SNF temporarily using either "dry storage," i.e., ISFSI, or "wet storage," i.e., SFP or SFPI [39]. Therefore, in this study, we assumed that all the SNFs to be produced at the Barakah site can be sent to a CDS facility or a PDF after 2040, although this date would depend on the operation start time of the interim storage facility.

Based on the aforementioned, the purpose of this work is to determine the optimal parameters from a wide range of options in the management of SNF that would enable the UAE to manage the removal of SNFs from pool storage for their transfer to interim storage.

\section{Materials and Methods}

2.1. Materials. To conduct this study, we devised a number of technical and financial basis assumptions based on the experiences of the US, South Korea, and Spain with regard to nuclear fuel management. The many possible SNF management strategies that can be implemented after the permanent shutdown of the Barakah site can be represented in a simple manner via the following visual plan. Specifically, flowcharts of possible spent fuel management strategies for the entire site and for one unit reactor are shown in Figures 3 and 5 , respectively.

Six possible ways for SNF management can be applied:

(1) If a repository is available, whether an off-site CDS or PDF, SNFs can be sent directly to the repository for permanent disposal without any interim storage during the decommissioning of NPPs using path options (3), (4), (6), and (8).

(2) If a repository is not available yet, as in most countries, SNFs should be temporarily stored until they can be sent to a repository through the use of options such as using path option (0), pool expansion, SFPI (1), or ISFSI (2).

(3) If the SFP option requires the modification of an existing spent fuel pool, or if the ISFSI option requires the construction of a dedicated facility, path options (0) to (2) can be pursued. 


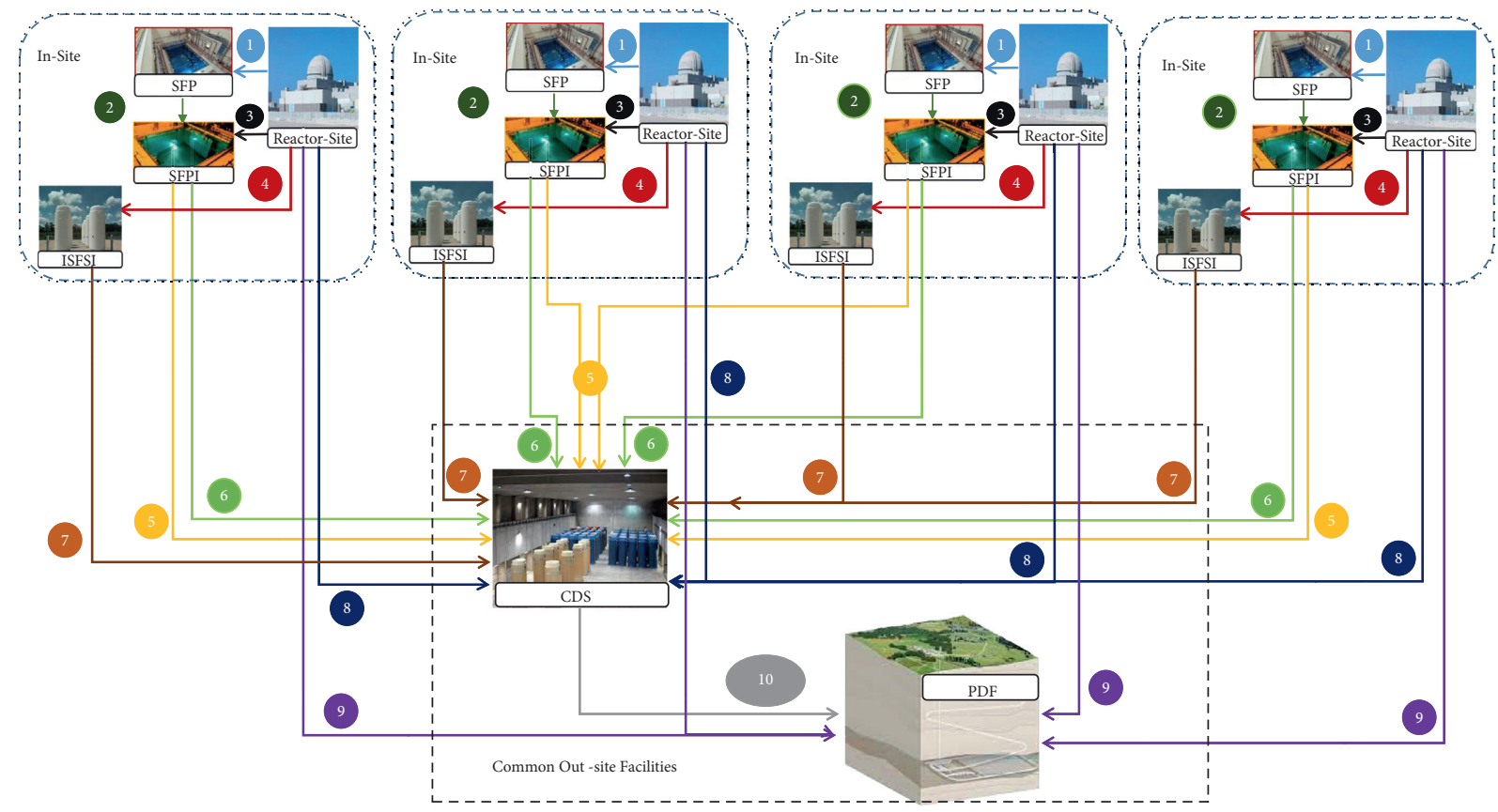

Figure 3: Chart of possible spent fuel management strategies for the Barakah site.

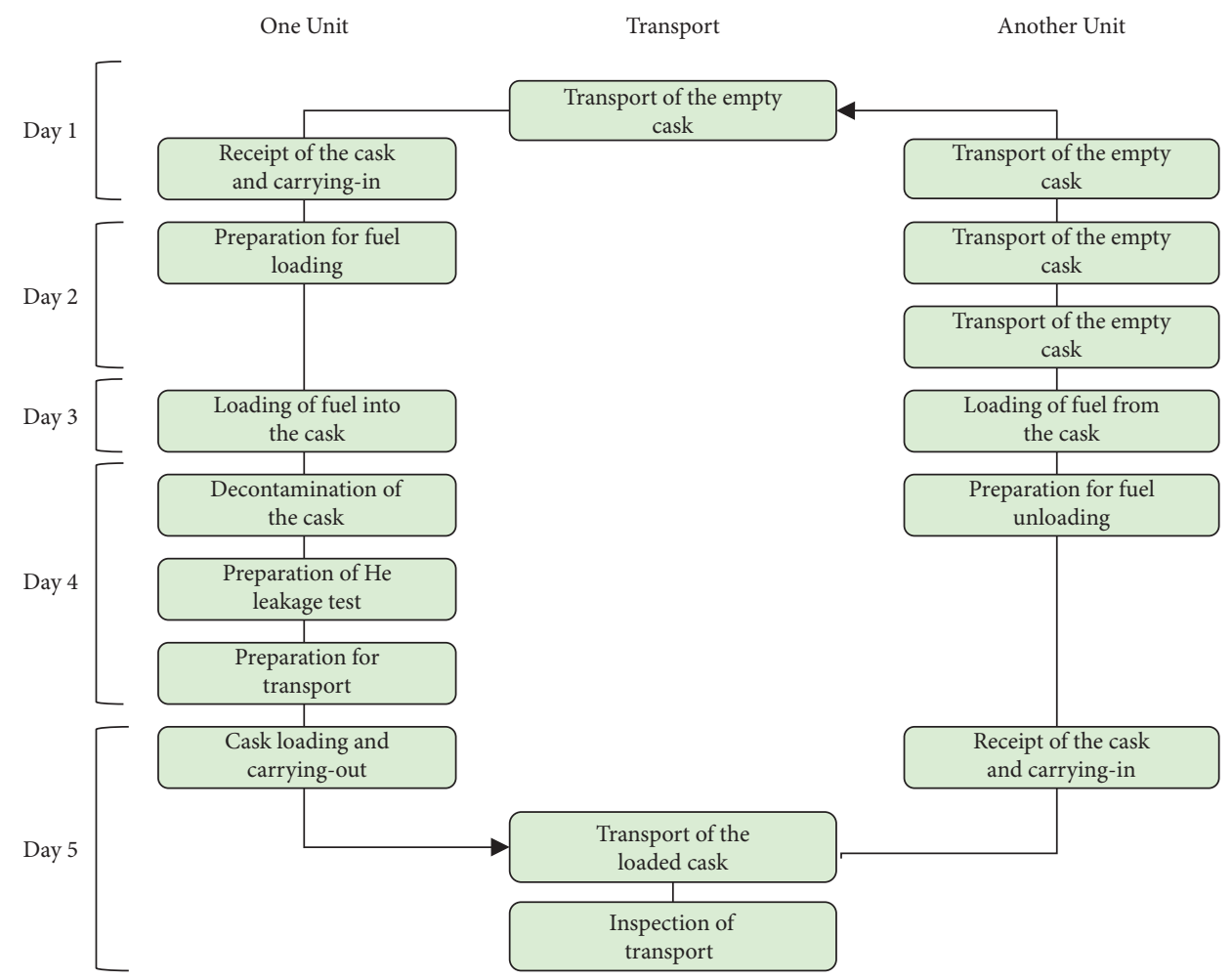

FIgURE 4: Stepwise procedures of on-site transport process [45].

(4) Sometimes path options (1), (2), and (5) and both SFPI and ISFSI can be employed in sequence [48].

(5) SNFs can be temporarily stored in casks and then sent to a CDS or PDF, as shown in path options (3) and (4).
(6) SNF can be sent to a reprocessing unit, as shown in path options (6) and (8). However, this option has been excluded from this study because of the UAE national policy strategy, which aims to not implement any type of reprocessing for nuclear fuel wastes [37]. 


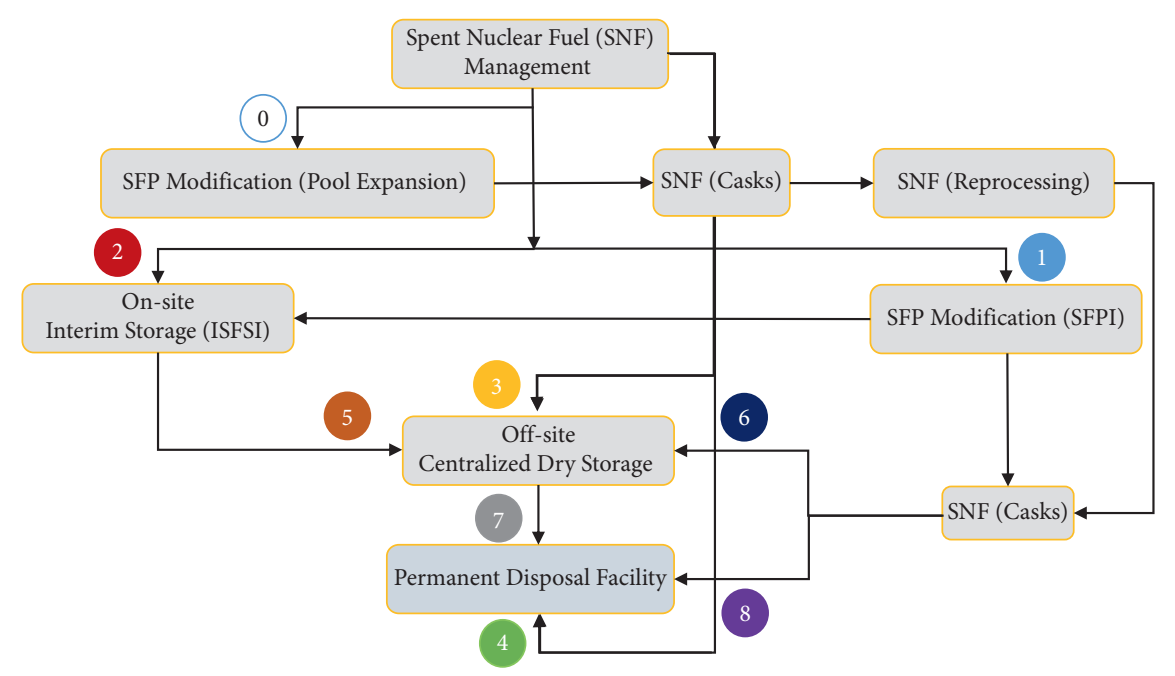

Figure 5: Flowchart of possible spent fuel management strategies for one unit reactor.

Recently, several reactors from around the world have been permanently shut down, such as in the US, where 35 reactors have been decommissioned [46-48]. Among these were a number of pressurized water reactors (PWRs), such as units 2 and 3 of the San Onofre Nuclear Generating Station (SONGS) in the US, which employed both SFPI and ISFSI for interim storage [46-50]. A number of other reactors, which are of the same reactor type as the Barakah units, will also shut down in the future [51]. Despite the many advantages of SFPI for spent fuel management, there has not yet been a project of this nature in Arab countries, including the UAE, and thus, there are some uncertainties about its application to the Barakah units. Therefore, to examine practical examples that are similar to the APR-1400 Barakah reactors, we performed case studies of the SONGS units 2 and 3 in the US, and the history of Spain with regard to its nuclear fuel management, focusing specifically on decommissioning cost analysis, and a review of previous studies.

We also calculated the major costs of facility storage and of cask technologies based on previous studies [51-57]. Considering that the Shin-Kori reactors 3 and 4 started their commercial operation in 2016 and 2019, respectively, with a 1.4 GWe installed capacity for each, and a total storage capacity of 780 fuel assemblies, we assumed a total accumulated capacity of 196 fuel assemblies, i.e., approximately $25 \%$ of the site capacity saturation, for Shin-Kori 3, and zero accumulated fuel assembly for Shin-Kori 4 . We also considered that both Shin-Kori 3 and 4 are expected to be shut down by the years 2081 and 2082 [50, 53].

2.2. Method. Several analytical methods have been used in previous studies regarding SNF management for power plants. Examples of these methods include projections of the discharge SNF and relevant cost analyses, and net present value and levelized unit cost analysis [3]. In one study, the researchers applied a system-engineering decision-making tool using the analytical hierarchical process (AHP) to estimate the best temporary system for SNF management [58].
Other studies used the decommissioning time schedules of decommissioned NPPs and estimated the amount of SNFs to be removed from the NPP; specifically, they performed costbenefit analyses using different storage system options or scenarios [39, 50, 52, 54, 56-58].

To the best of our knowledge, all of these previous studies have resulted in limited optimal options. Even though these studies developed cost solutions for SNF management, they did not include more economic parameters, such as the inflation and incremental escalation rates, nor the six main cost categories for the facilities and cask storages. Furthermore, these previous studies were limited in terms of the variety in storage facilities that were investigated, durations of processes, time periods applied for the storage facilities, and switching operation modes that were included in the analysis. Therefore, these studies were limited in their cost category solutions, as will be illustrated later. In this study, we attempted to provide a wide range of optimal options with a variety of cost category solution options for SNF management using the net present value, in line with the decommissioning time schedules. For our analyses, we used the software programs MS Project and MATLAB [59].

The key group scenario assumptions were devised based on practical approaches for estimating SNF management. These assumptions include the following:

Performing cost evaluations using the decommissioning period schedules

Estimating SNF generation and transportation prospects at the Barakah site

Evaluating the specifications of varied types of spent fuel transport casks

Estimating the number of spent fuel assemblies and required number of transports

Estimating the transport period, based on a 7-year condition of using transport cask models

Estimating the costs of different casks, such as KN-12, concrete, metal, and dual-purpose casks (DPC) [51] 
The major and unit costs for spent fuel management were calculated via application of a switching operation mode $(\mathrm{ON}=1, \mathrm{OFF}=0)$.

2.2.1. Scenario Assumptions and Considerations. For each NPP, we devised eight time-period scenarios and applied storage times of $20,40,30$, and 60 years for each storage facility based on the cooling durations of the fuel assemblies (FAs) involved in each SNF management option. These scenarios, as outlined in Table 2, are as follows:

Scenario 1 (Sc-1): after shutdown, the SNF will be stored in casks for 60 years as a separate island in a nearby pool, referred to as an SPFI storage, and then transferred to and stored in a CDS or PDF for 20 years, i.e., $\mathrm{SFPI}=60$, ISFSI $=0, \mathrm{CDS}=20$, and $\mathrm{PDF}=20$ years of storage, symbolized by (60-0-20-20) [39]

Scenario-2 (Sc-2): after shutdown, the SNF will be stored in casks for 60 years in a dry storage, referred to as an ISFSI storage, and then transferred to and stored in a CDS or PDF for 20 years, i.e., SFPI $=0$, ISFSI $=60$, $\mathrm{CDS}=20$, and $\mathrm{PDF}=20$ years of storage, symbolized by (0-60-20-20) [39]

Scenario-3 (Sc-3): the SFP will be expanded to store the SNF for 20 years; consequently, the SNF will be stored in an SFPI storage facility for 40 years, whereas the remaining time period, i.e., 20 years, will be allotted for the storage of FAs in an ISFSI storage facility, after which the SNFs will be transferred directly to and stored in a CDS or PDF for 20 years, i.e., SFPI $=40$, ISFSI $=20, C D S=20$, and $P D F=20$ years of storage, symbolized by (40-20-20-20)

Scenario-4 (Sc-4): the SFP will be expanded to store the SNF for 40 years; consequently, the SNF will be stored in an SFPI storage facility for 20 years, whereas the remaining time period, i.e., 40 years, will be allotted for the storage of FAs in an ISFSI storage facility, after which the SNFs will be transferred directly to and stored in a CDS or PDF for 20 years, i.e., SFPI $=20$, ISFSI $=40, C D S=20$, and $P D F=20$ years of storage, symbolized by (20-40-20-20)

Scenario-5 (Sc-5): the SFP will be expanded to store the SNF for 30 years; consequently, the SNF will be stored in an SFPI storage facility for 30 years, whereas the remaining time period, i.e., 30 years, will be allotted for the storage of FAs in an ISFSI storage facility, after which the SNFs will be transferred directly to and stored in a CDS or PDF for 20 years, i.e., $\mathrm{SFPI}=30$, ISFSI $=30, \quad \mathrm{CDS}=20$, and $\mathrm{PDF}=20$ years of storage, symbolized by (30-30-20-20)

Scenario-6 (Sc-6): the SNF will be stored in an SFPI storage facility for 20 years, whereas the remaining time period, i.e., 20 years, will be allotted for the storage of FAs in an ISFSI storage facility, after which the SNFs will be transferred directly to and stored in a CDS or PDF for 20 years, i.e., SFPI $=20$, ISFSI $=20, C D S=20$, and $\mathrm{PDF}=20$ years of storage, symbolized by (20-2020-20)
Scenario-7 (Sc-7): the SNF will be stored in pools for 20 years, stored in casks as a separate island in a nearby pool, referred to as an SPFI storage, and then transferred to and stored in a CDS or PDF for 20 years, i.e., $\mathrm{SFPI}=20$, ISFSI $=0, \mathrm{CDS}=20$, and $\mathrm{PDF}=20$ years of storage, symbolized by (20-0-20-20)

Scenario-8 (Sc-8): the SNF will be stored in pools for 20 years, stored in casks as a separate island near the pool, referred to as an ISFSI storage, and then transferred to and stored in a CDS or PDF for 20 years, i.e., $\mathrm{SFPI}=0$, ISFSI $=20, C D S=20$, and $P D F=20$ years of storage, symbolized by (0-20-20-20)

In addition, technical and economic analyses and evaluations of the aforementioned eight time-period scenarios were conducted accordingly for the interim storage of the SNF.

\subsubsection{Current Status of Nuclear Fuel and SNF Generation,} and Transportation Prospect of Barakah Site. For each NPP, it is important to examine the status in terms of the amount of SNF and to determine the future prospects of the plant. Therefore, in this study, because the reactor designs and FA capacities of the Barakah site are similar to those of ShinKori units 3 and 4, we utilized the data for Shin-Kori units 3 and 4, specifically those that are relevant to the fuel assembly based on the commercial operation and expiration date of the Barakah site. The number of fuel assemblies (FA) generated by the Shin-Kori site, as of the third quarter of 2020, can be expressed in brake units 1, 2, 3, and 4, as shown in Table 3 [2, 41-44].

After the amount of FA to be transported on-site is estimated, appropriate available technologies for transporting the SNFs to nearby units, storage facilities, or disposal facilities using a transport container should be identified. Thus far, South Korea has developed several types of spent fuel transport casks, and, in this study, we specifically adopted technologies developed by KHNP that have been applied to the Kori site. Among these technologies are a KN-12 transport container that is capable of carrying 12 fuel assemblies of PWR spent fuel per transport, and concrete, metal, and DPC casks that are each capable of carrying 17 PWR fuel assemblies [44, 45, 51-60].

It is also important to identify the number of spent fuel assemblies and the required number of transports for each NPP after the expected Barakah site shutdown. In particular, for each NPP, we should calculate the total number of fuel assemblies by adding the quantity of FAs in the SFP and the FAs in-core, as shown in Table 3. We should then estimate the number of transports via division of the total quantity of FAs by the KN-12 cask capacity, i.e., 12 FAs, and by the capacities of the other types of casks, such as concrete, metal, and DPC casks, i.e., 17 FAs. These calculations result in approximately 29 transports per refuelling for a KN-12 cask, and 21 transports per refuelling for any of the three other types of casks, based on an assumption that each refuelling cycle was approximately 18 months. Consequently, the approximate transport schedule based on a 7-year condition 
TABLE 2: Scenario duration assumptions and considerations.

\begin{tabular}{llccc}
\hline \multirow{2}{*}{ Scenarios } & \multicolumn{1}{c}{ Types of casks used } & \multicolumn{2}{c}{ Storage facilities } \\
& & SFPI & ISFSI & PDF \\
\hline Sc-1 & KN-12, concrete, metal, and DPC & 60 years & 0 years & 20 years \\
Sc-2 & KN-12, concrete, metal, and DPC & 0 years & 60 years & 20 years \\
Sc-3 & KN-12, concrete, metal, and DPC & 40 years & 20 years & 20 years \\
Sc-4 & KN-12, concrete, metal, and DPC & 20 years & 40 years & 20 years \\
Sc-5 & KN-12, concrete, metal, and DPC & 30 years & 30 years & 20 years \\
Sc-6 & KN-12, concrete, metal, and DPC & 20 years & 20 years & 20 years \\
Sc-7 & KN-12, concrete, metal, and DPC & 20 years & 0 years & 20 years \\
Sc-8 & KN-12, concrete, metal, and DPC & 0 years & 20 years & 20 years \\
\hline
\end{tabular}

TABLE 3: Spent fuel generation status of Barakah site.

\begin{tabular}{|c|c|c|c|c|}
\hline \\
\hline \multicolumn{5}{|l|}{$\begin{array}{l}\text { Barakah site } \\
\text { Unit \# }\end{array}$} \\
\hline Construction (yr) & 2012 & 2013 & 2014 & 2015 \\
\hline Commercial operation (yr) & 2020 & $2022^{*}$ & $2023^{*}$ & $2024^{*}$ \\
\hline Design life expiration (yr) & 2080 & $2082^{*}$ & $2083^{*}$ & $2084^{*}$ \\
\hline Refuelling cycle (month) & 18 & $18^{*}$ & $18^{*}$ & $18^{*}$ \\
\hline In-core fuel (FAs) & 241 & $241^{*}$ & $241^{*}$ & $241^{*}$ \\
\hline SFP capacity (FAs) & 780 & $780^{*}$ & $780^{*}$ & $780^{*}$ \\
\hline SFP storage for year 2020 (FAs) & $1333.4^{*}$ & $1333.4^{*}$ & $1333.4^{*}$ & $1333.4^{*}$ \\
\hline SFP storage for year 2040 (FAs) & $2666.8^{*}$ & $2666.8^{*}$ & $2666.8^{*}$ & $2666.8^{*}$ \\
\hline SFP storage for year 2060 (FAs) & $4174.5^{*}$ & $4174.5^{*}$ & $4174.5^{*}$ & $4174.5^{*}$ \\
\hline
\end{tabular}

*Expectation.

for the four types of casks can be calculated through the addition of 7 years after the reactor shutdown. The calculated values are summarized in Table 4.

Another essential factor to consider that affects the operation cost during on-site transport is the transport period. In this study, we adopted the spent fuel transportation schedule for Kori units 1, 2, 3, and 4, which have already been applied in a previous case study, with the application of additional assumptions in the calculation of the transportation period. We also adopted on-site transport experience relevant to the Kori NPP, accounted for the required 7 years of cooling for the casks, and assumed that the SNFs are transported immediately after the required 7year reactor cooling period.

The transport of damaged nuclear fuel (hypothetical accident), which was assumed to require the use of another cask, was excluded from this study. The implementation of transshipment stepwise procedures, and the sequence of events that SNFs undergo during the on-site transport process, via one of the four types of transport casks, within a day's duration, are illustrated in Figure 5. This chart is based on the experiences of engineers and researchers who have conducted similar procedures in the past [44-60].

In addition, the spent fuel management scenario schedule for each plant was prepared using MS Project software. The schedule accounts for the SFP, SFPI, ISFSI, CDS, and PDF, and the activities and their time durations, starting from the NPP shutdown, transition, D\&D, SFP or SFPI operation, SNF transfer to CDS and PDF facilities, SFPI $(\mathrm{D} \& \mathrm{D})$, site remediation, and site opening. In this way, for all Barakah sites (i.e., Barakah 1, 2, 3, and 4) and for all types of storage facilities, we summarized all activities of the decommissioning phase, starting from the shutdown of the reactor to the stage of site re-opening, to enable these facilities to be used in a secure and safe way. The time shifts between these processes, as shown in Table 5, were taken into account. We then applied these schedules to the eight scenarios outlined earlier in Table 2 (i. e., the shifting SFPI and ISFSI operation time periods are taken into account through the addition of 20 years between the start and finish times for each reactor) and present the revised schedules in Table 6.

2.2.3. Data Preparation and Cost Calculation. Overall, previous studies have used a large amount of data related to the costs of facilities, storage, and casks. Nonetheless, the total cost of the backend of a nuclear fuel cycle can be summarized as follows:

(1) Cost of facilities: investment cost, operation and maintenance (O\&M) cost, and decommissioning

(2) Costs for cask and loading, which are calculated after SNF unloading from the pool for each reactor, and transportation costs, which are calculated between facilities

The cost assumptions for these items were applied based on the IAEA international conference and other published papers [61]. We assumed the cost of the KN-12 cask to be approximately 5.0 million USD/cask, whereas the cost assumptions for the other three types of casks were applied based on a recent study and experiences involving 200 casks 
TABLE 4: Estimated transport periods based on 7-year condition for four types of casks.

\begin{tabular}{|c|c|c|c|c|}
\hline NPP & Number of transports & Start (date) & End (date) & Duration (yr) \\
\hline Barakah-1 & 29 or 21 & Jun-2087 & Jan-2089 & 1.6 \\
\hline Barakah-2 & 29 or 21 & Apr-2089 & Nov-2091 & 1.6 \\
\hline Barakah-3 & 29 or 21 & Jun-2090 & Jan-2092 & 1.6 \\
\hline Barakah-4 & 29 or 21 & Nov-2093 & Jun-2095 & 1.6 \\
\hline
\end{tabular}

TABLE 5: Spent fuel transportation schedule for all Barakah sites.

\begin{tabular}{|c|c|c|c|c|c|c|c|c|}
\hline \multirow{2}{*}{ SFPI } & \multicolumn{2}{|c|}{ Barakah-1 } & \multicolumn{2}{|c|}{ Barakah-2 } & \multicolumn{2}{|c|}{ Barakah-3 } & \multicolumn{2}{|c|}{ Barakah-4 } \\
\hline & Start & Finish & Start & Finish & Start & Finish & Start & Finish \\
\hline NPP shutdown & $6 / 1 / 2080$ & & $4 / 1 / 2082$ & & $6 / 1 / 2083$ & & $6 / 1 / 2084$ & \\
\hline Transition & $6 / 1 / 2080$ & $6 / 1 / 2085$ & $4 / 1 / 2082$ & $4 / 1 / 2087$ & $6 / 1 / 2083$ & $6 / 1 / 2088$ & $6 / 1 / 2084$ & $6 / 1 / 2089$ \\
\hline $\mathrm{D} \& \mathrm{D}$ & $6 / 1 / 2085$ & $6 / 1 / 2091$ & $4 / 1 / 2087$ & $4 / 1 / 2093$ & $6 / 1 / 2088$ & $6 / 1 / 2094$ & $6 / 1 / 2089$ & $6 / 1 / 2095$ \\
\hline SFPI operation & $6 / 1 / 2087$ & $6 / 1 / 2102$ & $4 / 1 / 2087$ & $4 / 1 / 2102$ & $6 / 1 / 2090$ & $6 / 1 / 2105$ & $6 / 1 / 2091$ & $6 / 1 / 2106$ \\
\hline SNF transfer to CDS & $6 / 1 / 2100$ & $6 / 1 / 2102$ & $6 / 1 / 2100$ & $6 / 1 / 2102$ & $6 / 1 / 2103$ & $6 / 1 / 2105$ & $6 / 1 / 2104$ & $6 / 1 / 2106$ \\
\hline SFPI D \& D & $6 / 2 / 2102$ & $6 / 2 / 2103$ & $6 / 1 / 2101$ & $6 / 1 / 2102$ & $6 / 1 / 2102$ & $6 / 1 / 2103$ & $6 / 1 / 2106$ & $6 / 1 / 2107$ \\
\hline Site remediation & $6 / 2 / 2103$ & $6 / 1 / 2105$ & $6 / 1 / 2102$ & $6 / 1 / 2104$ & $6 / 1 / 2103$ & $6 / 1 / 2105$ & $6 / 1 / 2107$ & $6 / 1 / 2109$ \\
\hline Site open & $6 / 1 / 2105$ & $12 / 1 / 2105$ & $6 / 1 / 2104$ & $6 / 1 / 2104$ & $6 / 1 / 2105$ & $6 / 1 / 2105$ & $6 / 1 / 2109$ & $6 / 1 / 2109$ \\
\hline \multicolumn{9}{|l|}{ ISFSI } \\
\hline NPP shutdown & $6 / 1 / 2080$ & & $4 / 1 / 2082$ & & $6 / 1 / 2083$ & & $6 / 1 / 2084$ & \\
\hline Transition & $6 / 1 / 2080$ & $6 / 1 / 2085$ & $4 / 1 / 2082$ & $4 / 1 / 2087$ & $6 / 1 / 2083$ & $6 / 1 / 2088$ & $6 / 1 / 2084$ & $6 / 1 / 2089$ \\
\hline SNF transfer to ISFSI & $6 / 1 / 2085$ & $12 / 1 / 2087$ & $4 / 1 / 2087$ & $10 / 1 / 2089$ & $6 / 1 / 2088$ & $12 / 1 / 2090$ & $6 / 1 / 2089$ & $12 / 1 / 2091$ \\
\hline $\mathrm{D} \& \mathrm{D}$ & $12 / 1 / 2087$ & $12 / 1 / 2093$ & $10 / 1 / 2089$ & $10 / 1 / 2095$ & $12 / 1 / 2090$ & $12 / 1 / 2096$ & $12 / 1 / 2091$ & $12 / 1 / 2097$ \\
\hline ISFSI operation & $12 / 1 / 2089$ & $12 / 1 / 2104$ & $10 / 1 / 2091$ & $10 / 1 / 2106$ & $12 / 1 / 2092$ & $12 / 1 / 2107$ & $12 / 1 / 2093$ & $12 / 1 / 2108$ \\
\hline SNF transfer to CDS & $1 / 1 / 2102$ & $1 / 1 / 2104$ & $10 / 1 / 2104$ & $10 / 2 / 2106$ & $12 / 1 / 2105$ & $12 / 1 / 2107$ & $12 / 1 / 2106$ & $12 / 1 / 2108$ \\
\hline Site remediation & $12 / 1 / 2105$ & $12 / 1 / 2107$ & $12 / 1 / 2107$ & $12 / 1 / 2109$ & $12 / 1 / 2107$ & $12 / 1 / 2109$ & $12 / 1 / 2109$ & $12 / 1 / 2111$ \\
\hline Site open & $12 / 1 / 2107$ & $12 / 1 / 2107$ & $12 / 1 / 2109$ & $12 / 1 / 2109$ & $12 / 1 / 2109$ & $12 / 1 / 2109$ & $12 / 1 / 2111$ & $12 / 1 / 2111$ \\
\hline
\end{tabular}

TABLE 6: Spent fuel transportation schedule showing effect of SFPI and ISFSI facility shifting times for all scenarios.

\begin{tabular}{lccccc}
\hline \multirow{2}{*}{ SFPI } & \multicolumn{2}{c}{ Barakah-Sc.1 } & \multicolumn{2}{c}{ Barakah-Sc.2 } & \multicolumn{2}{c}{ Barakah-Sc.3 } \\
& Start & Finish & Start & Finish & $6 / 1 / 2080$ \\
NPP shutdown & $6 / 1 / 2080$ & & $6 / 1 / 2080$ & & $6 / 1 / 2080$ \\
Transition & $6 / 1 / 2080$ & $6 / 1 / 2085$ & $6 / 1 / 2080$ & $6 / 1 / 2085$ & $6 / 1 / 2085$ \\
D \& D & $6 / 1 / 2085$ & $6 / 1 / 2091$ & $6 / 1 / 2085$ & $6 / 1 / 2091$ & $6 / 1 / 2091$ \\
SFPI operation & $6 / 1 / 2087$ & $6 / 1 / 2107$ & $6 / 1 / 2087$ & $6 / 1 / 2127$ & $6 / 1 / 2087$ \\
SNF transfer to CDS & $6 / 1 / 2105$ & $6 / 1 / 2107$ & $6 / 1 / 2125$ & $6 / 1 / 2127$ & $6 / 1 / 2105$ \\
SFPI D \& D & $6 / 2 / 2107$ & $6 / 2 / 2108$ & $6 / 2 / 2127$ & $6 / 2 / 2128$ & $6 / 2 / 2107$ \\
Site remediation & $6 / 2 / 2108$ & $6 / 1 / 2110$ & $6 / 2 / 2128$ & $6 / 1 / 2130$ & $6 / 2 / 2108$ \\
Site open & $6 / 1 / 2110$ & $6 / 1 / 2110$ & $6 / 1 / 2130$ & $6 / 1 / 2130$ & $6 / 1 / 2110$ \\
\hline ISFSI & & & & $6 / 2107$ \\
NPP shutdown & $6 / 1 / 2080$ & & $6 / 2107$ & $6 / 1 / 2110$ \\
Transition & $6 / 1 / 2080$ & $6 / 1 / 2085$ & $6 / 1 / 2080$ & $6 / 1 / 2085$ & $6 / 1 / 2080$ \\
SNF transfer to ISFSI & $6 / 1 / 2085$ & $12 / 1 / 2087$ & $6 / 1 / 2085$ & $12 / 1 / 2087$ & $6 / 1 / 2080$ \\
D \& D & $12 / 1 / 2087$ & $12 / 1 / 2093$ & $12 / 1 / 2087$ & $12 / 1 / 2093$ & $12 / 1 / 2087$ \\
ISFSI operation & $12 / 1 / 2089$ & $12 / 1 / 2109$ & $12 / 1 / 2089$ & $12 / 1 / 2109$ & $12 / 1 / 2089$ \\
SNF transfer to CDS & $1 / 1 / 2107$ & $1 / 1 / 2109$ & $1 / 1 / 2107$ & $1 / 1 / 2109$ & $1 / 1 / 2127$ \\
Site remediation & $12 / 1 / 2110$ & $12 / 1 / 2112$ & $12 / 1 / 2110$ & $12 / 1 / 2112$ & $12 / 1 / 2130$ \\
Site open & $12 / 1 / 2112$ & $12 / 1 / 2112$ & $12 / 1 / 2112$ & $12 / 1 / 2112$ & $12 / 1 / 2132$ \\
\hline
\end{tabular}

of 10 -MTU cask capacity. For a cask that is able to hold 21 FAs, the costs of concrete, metal, and DPC casks were approximately $0.845066,2.994982$, and 3.767186 million USD/cask, respectively, whereas the O\&M cost was 1.75 million USD/year [5, 50, 61-64].

However, all the aforementioned costs were for the year 2010, and may therefore be outdated, whereas facility cost items, such as investment cost (fixed and variable), O\&M cost (fixed and variable), loading, transportation, and decommissioning costs for the SFPI, ISFSI, CDS, and PDF facilities were assumed based on the assumptions for another case study after the EUR-to-USD conversion price for 2017, or approximately 1.13, was adapted. The EUR prices are shown in Table 7.

Converted to USD, the fixed-cost investments for CDS and PDF for the year 2020 were approximately 310.7 and 
757.1 million USD, respectively; the variable-cost investments were approximately 1.4 and 0.4 million USD/cask, respectively; the O\&M costs were approximately 19.2 and 73.4 million USD/year, respectively; and the loading and transportation costs were approximately 1.0 million USD/ cask for both technologies [5, 9, 15, 37, 61, 65].

All the aforementioned costs for the storage technologies examined in this study were for the years 2014 and 2017 and have been normalized forward to the year 2020 based on an assumption that the UAE and South Korea have the same levels of economic parameters as those of the US [61, 63-65]. Therefore, to approximate the current economic environment in 2020 for all types of SNF storage facilities and casks technologies for the time period of operation, we assumed a nominal discount rate from the revised Appendix $\mathrm{C}$ of Circular A-94 from the Office of Management and Budget in Washington, DC [66]. We also considered other parameters relevant to the US economic environment, such as the inflation rate and incremental escalation (based on histories of past nuclear projects) in our calculations. We assumed the following rates shown in Table 8 [66-68].

The normalized costs of the facilities and casks have been forwarded to the reference year (i.e., 2020) for cost assessment using the economic parameters shown in Table 8 for all items and the NPV, as shown in Tables 9 and 10, which is applied using the following equation $[5,35,50,68]$ :

$$
N P V=\frac{\text { Base Cost. }\left(1+I_{\text {inf }}\right)^{t} \cdot\left(1+I_{\text {inc esc }}\right)^{t}}{\left(1+I_{d}\right)^{n}},
$$

where $I_{\text {inf }}$ is general inflation rate, $I_{\text {ins esc }}$ is incremental escalated rate, $I_{d}$ is nominal discount rate, and $t$ is the number of years after the base year.

We applied equations (2) to (7) to calculate the six cost items for the facilities and cask storages. Table 11 shows the definitions of the variables and indexes included in the equations $[5,35]$.

(1) Items costs for the facilities:

$$
\begin{aligned}
\text { investment cost } & =\sum_{i} \sum_{t=T 0 i}^{T 1 i} \frac{\left(I_{F i}+I_{V i} \cdot C_{i}\right) \cdot\left(1+I_{\text {inf }}\right)^{t} \cdot\left(1+I_{\text {incesc }}\right)^{t} / \Delta T_{C i}}{(1+r)^{t}}, \\
\text { O \& M cost } & =\sum_{i} \sum_{t=T 1 i}^{T f i} \frac{\left(O_{i}\right) \cdot\left(1+I_{\text {inf }}\right)^{t} \cdot\left(1+I_{\text {incesc }}\right)^{t}}{(1+r)^{t}}, \\
\text { decommissioning cost } & =\sum_{i} \sum_{t=T f i}^{T i} \frac{D_{i} \cdot\left(1+I_{\text {inf }}\right)^{t} \cdot\left(1+I_{\text {incesc }}\right)^{t} / \Delta T_{D i}}{(1+r)^{t}} .
\end{aligned}
$$

(2) Items costs for the casks:

$$
\begin{aligned}
\text { casks cost } & =\sum_{k} \sum_{t=T 0}^{T 1} \frac{C_{k} \cdot N_{C K t} \cdot\left(1+I_{\text {inf }}\right)^{t} \cdot\left(1+I_{\text {incesc }}\right)^{t}}{(1+r)^{t}}, \\
\text { investment cost } & =\sum_{k} \sum_{t=T 0}^{T 1} \frac{C_{K} \cdot N_{C K t} \cdot\left(1+I_{\text {inf }}\right)^{t} \cdot\left(1+I_{\text {incesc }}\right)^{t}}{(1+r)^{t}}, \\
\text { transportation cost } & =\sum_{k j} \sum_{t=T 0 j}^{T 1 j} \frac{T_{j} \cdot N_{C j t} \cdot\left(1+I_{\text {inf }}\right)^{t} \cdot\left(1+I_{\text {incesc }}\right)^{t}}{(1+r)^{t}} .
\end{aligned}
$$

2.2.4. Spent Fuel Management Options for Barakah Site Calculated Using MATLAB. Because of the complicated variety of options that need to be calculated in this study, we performed our analyses using the MATLAB software, which was designed to be used by engineers and scientists specifically to analyze and design systems. In particular, we used the "Global Optimization" toolbox that is available in the MATLAB software [59]. Moreover, we assumed two symbols, i.e., "0" (zero) and " 1 " (one), to represent the switching mode operation of the facility storage. For all scenarios, a switch on is represented by " 1 " (one), whereas a switch off is represented by "0" (zero). We also reflected on all possible operation options, costs for the combined facilities, and types of cask storages within the summarized system $(\mathrm{ON}=1, \mathrm{OFF}=0)$, as shown in Tables 12 and 13. For the four reactors of the Barakah site, the different time-period scenarios for the storage facilities, which are outlined in Table 2, and the switching mode matrix $(\mathrm{ON}=1$, $\mathrm{OFF}=0$ ), which is shown in Table 12 , are applied with the value 
TABLE 7: Summary of cost assumptions.

\begin{tabular}{|c|c|c|c|c|c|}
\hline Type & SPFI & ISFSI & CDS & PDF & Units \\
\hline Investment (fixed) & 1.827 & 15 & 275 & 670 & M EUR \\
\hline Investment (variable) & 0 & 0.15 & 0.409 & 0.359 & M EUR/cask \\
\hline O\&M (first years) & 0 & 0.5 & 17 & 65 & M EUR/year \\
\hline O\&M (last years) & 0.77433 & 1.25 & 26 & 32.5 & M EUR/year \\
\hline Loading & 0.265 & 0.265 & 0.265 & 0.265 & M EUR/cask \\
\hline Transportation & 0 & 0.53 & 0.63 & 0.63 & M EUR/cask \\
\hline Decommissioning & $.15 \%$ of invest & $.15 \%$ of invest & $.15 \%$ of invest & 260 & M EUR/cask \\
\hline
\end{tabular}

TABLE 8: Environmental economic parameters of 2020 [66-68].

\begin{tabular}{lc}
\hline Item & Rate (\%/year) \\
\hline General inflation rate & 1.2 \\
Incremental escalated rate & 3.0 \\
Nominal discount rate & 1.5 \\
\hline
\end{tabular}

TABLE 9: Normalized cost categories for SFPI and ISFSI facility options from year 2014 forward to 2020.

\begin{tabular}{lccccc}
\hline Item & SPFI & ISFSI & CDS & PDF & Units \\
\hline Investment (fixed) & 2.07 & 16.95 & 310.75 & 757.10 & (M USD) \\
Investment (variable) & 0.00 & 0.17 & 1.41 & 0.41 & (M USD/cask) \\
O\&M (first years) & 0.9 & 1.4 & 29.4 & 36.7 & (M USD/year) \\
Loading & 0.30 & 0.30 & 0.30 & 0.30 & (M USD/cask) \\
Transportation & 0.00 & 0.60 & 0.72 & 0.72 & (M USD/cask) \\
Decommissioning & 15\% of investment & 15\% of investment & 15\% of investment & 260.0 & (M USD/cask) \\
\hline
\end{tabular}

TABLE 10: Normalized cask cost options from year 2017 forward to 2020.

\begin{tabular}{lccc}
\hline KN-12 casks (M USD/cask) & Concrete casks (M USD/cask) & Metal casks (M USD/cask) & DPC (M USD/cask) \\
\hline 6.52 & 0.845066 & 2.994982 & 3.767186 \\
\hline
\end{tabular}

Table 11: Definitions of variables and indexes in equations (1) to (6).

\begin{tabular}{|c|c|}
\hline \multicolumn{2}{|c|}{ List of variables and indexes } \\
\hline Index & Meaning \\
\hline $\bar{i}$ & Facility \\
\hline$j$ & Transportation between facilities in nuclear power plant \\
\hline$k$ & Nuclear power plant \\
\hline$t$ & Time period \\
\hline$r$ & Discount rate $\mathrm{ra}^{\mathrm{a}, 1}$ \\
\hline$T 0 i$ & Year of construction start \\
\hline$T 1 i$ & Year of operation start \\
\hline$T f i$ & Year of operation end \\
\hline $\mathrm{Ti}$ & Final year of decommissioning \\
\hline$T 0 j$ & Year of transportation start \\
\hline$T 1 j$ & Year of transportation end \\
\hline T0 & Year of reference \\
\hline $\mathrm{Ti}$ & Final year of period reference \\
\hline$I_{\text {inc esc }}$ & Incremental escalated rate \\
\hline$I_{F i}$ & Total fixed investment cost for facility type \\
\hline$I_{v i}$ & Total variable investment cost for facility type \\
\hline$O_{i}^{n}$ & O\&M cost per year \\
\hline$D_{i}$ & Total cost of decommissioning \\
\hline$T_{j}^{l}$ & Transportation cost \\
\hline$C_{k}$ & Cask cost \\
\hline$L_{k}$ & Load cost \\
\hline$C_{i}$ & Capacity of facility \\
\hline$N_{c j t}$ & Number of casks transported on year $t$ per facility \\
\hline$N_{c k t}$ & Number of casks loaded on year $t$ per NPP \\
\hline$\Delta T_{c i}$ & Time period of facility construction \\
\hline$\Delta T_{D i}^{a}$ & Time period of facility decommissioning \\
\hline$I_{\text {inf }}$ & General inflation rate \\
\hline
\end{tabular}


costs incurred for each unit based on the main eight time-period scenarios, where each scenario involves four types of storage facilities and four types of cask technologies. Therefore, each scenario could be applied to 16 permutations of storage and casks, resulting in an array of $8 \times 16$ scenario options. For all cost calculations, the reference year was assumed to be 2020 .

We determined our switch operation mode cost values by replacing each $(\mathrm{ON}=1, \mathrm{OFF}=0)$ operation mode option, as outlined in Table 12, with its equivalent cost value, as calculated using equations (2)-(7) and using the assumed parameters in Tables 9 and 10. The operation mode options in terms of total cost values are shown in Table 13.

To calculate the overall probabilities of the operating modes, i.e., all possibilities of combining the storage facilities and technologies with the four types of casks utilized in this study, we multiplied $15^{4}$ operation mode options by a matrix of eight time-period scenarios, which we then multiplied by 16 permutations of storage and casks per scenario. The result is a matrix of $154 \times 16=810000$ possibilities, as shown in Figure 6. Therefore, we constructed our in-house MATLAB tool to generate the switching operation mode probability for a $15^{4} \times 8 \times 16$ matrix of $6,480,000$ possibilities, as shown in Figure 7.

2.3. Overall Approach and Procedure. The overall approach and procedure adopted in this study are concisely depicted in Figure 8.

\section{Results and Discussion}

For the four reactors of the Barakah NPP, eight groups of time-period scenarios were evaluated for storage duration periods of 20,30, 40, and 60 years using the MATLAB software. The evaluation was based on the main factors that affect spent fuel management at the Barakah site, as explained in Sections 1.2, 1.3, and 2.1; the assumptions and input parameters detailed in Tables 1 to 10 ; and the assumption of 60 years of operational lifetime, as explained in Section 2.2.2. The main results, which are summarized in Tables 14 and 15, show that Sc-7 is the best and most economically favorable option among the tested scenarios, because it has the lowest cost category compared with the others. In Sc-7, the SNF is transferred to an SFPI facility 20 years after the reactor starts its operations. The SNF is stored in the wet storage for 20 years, after which it is sent directly to and stored for 20 years in a PDF facility that utilizes concrete casks.

Figure 9(a) shows the ranges of possible costs for all scenarios as functions of the relative possibility, within a range of 0 to 7,000 frequent possibilities (i.e., cumulative distribution frequency). The cost can reach 7,000 million USD. Among the tested scenarios, Sc- 2 and Sc-1 exhibited the highest frequencies among the cost options. However, as can be observed for Sc-7, as illustrated in Figure 9(b), the SFPI and PDF facilities have greater probabilities of leading to significantly lower-cost options compared with those for the other facilities in the other scenarios, as shown in Figure 9(a). The maximum cost for Sc-7, at approximately
5,000 million USD, makes it the least expensive among the time-period scenarios. It is then followed by Sc- 8 as the second least costly option, as shown in Figure 9(b).

Figure 10(a) shows the cost versus cumulative distribution frequency for the SFPI and PDF facilities, where Scs2, 4, and 5 exhibited the highest cost options, whereas Sc-7, further visualized in Figure 10(b), exhibited the lowest cost options, followed by Sc-8. Moreover, Sc-7 resulted in cost reductions of approximately 15\%, 19\%, 14.6\%, 13.1\%, 8\%, $6 \%$, and $5 \%$ compared to Sc-1, Sc-2, Sc-3, Sc-4, Sc-5, Sc-6, and $\mathrm{Sc}-8$, respectively. Sc-2 resulted in the highest cost among the tested scenarios because of the incremental cost category compared to those for the other scenarios. For further analysis of the cost category and facility cost in relation to the total cost, Figures 11 and 12 show the cost contributions of each cost category and facility storage technology, respectively, in percentages of the total cost for each scenario.

Figure 11 shows a more detailed view of Sc-7 in terms of the total cost for each facility (SFPI, CDS, and PDF) when different types of cask storage are utilized. From an economic and technical point view, the concrete cask storage was determined to be the best cask storage. Although the fixed investment cost of the PDF was assumed to be higher than those of the SPFI, ISFSI, and CDS facilities, as shown in Table 8, Figure 12 reveals that the CDS facility had the highest cost among all tested facilities in Sc-7, because of the effect of variable-cost investments. The variable-cost investment for the CDS is higher by approximately $100 \%$, $88.8 \%$, and $71.0 \%$ than those for the SFPI, ISFSI, and PDF, as shown in Table 8.

Therefore, based on the data for Sc-7, only the SFPI and PDF facilities will be considered. Furthermore, the scenario will be represented by 20-0-0-20, instead of 20-0-20-20, as shown in Figure 13, which visualizes the total cost per cost category based on Sc-7 for different types of cask storage. Figure 13 also shows the total cost category of Sc-7 for the SFPI and PDF facilities 20 years after the start of reactor shutdown for different types of cask storage.

Figure 14 shows that the cost categories have almost the same distribution among all tested scenarios. In addition, within each scenario, the investment costs are the most significant, followed by the costs for O\&M, decommissioning, transportation, cask storage, and cask loading. Figures 10 and 15 consistently show that $\mathrm{Sc}-7$ is the least expensive among the tested scenarios, followed by Sc- 8 and Sc-6, because the SFPI facility has the lowest cost. By contrast, $\mathrm{Sc}-2$ is the most expensive scenario because of the high costs of the ISFSI and PDF facilities.

On the other hand, the breakdown costs of these cost categories will be increased by the years 2020, 2040, 2050, 2060, and 2080, as shown in Figure 16, which illustrates the costs for each category in millions of US dollars.

In addition, the costs for the O\&M and decommissioning cost categories that are relevant to the investment cost, as visualized via the height shares, in comparison to those for the other cost categories, for the years 2020, 2040, 2050, 2060, and 2080, will reach 39.1\%, 54.9\%, 55.7\%, 58.3\%, and $66.1 \%$, respectively, for the O\&M cost, and $30.9 \%$, 
TABLE 12: $(\mathrm{ON}=1$ and $\mathrm{OFF}=0)$ switching operation mode for $(\mathrm{W}, \mathrm{D}, \mathrm{C}$, and $\mathrm{P})$ facility options in Barakah site.

\begin{tabular}{|c|c|c|c|c|c|c|c|c|c|c|c|c|c|c|c|c|}
\hline \multirow{2}{*}{ Operation mode options } & \multicolumn{4}{|c|}{ Barakah-1 } & \multicolumn{4}{|c|}{ Barakah-2 } & \multicolumn{4}{|c|}{ Barakah-3 } & \multicolumn{4}{|c|}{ Barakah-4 } \\
\hline & $\mathrm{W}$ & $\mathrm{D}$ & $\mathrm{C}$ & $\mathrm{P}$ & W & $\mathrm{D}$ & $\mathrm{C}$ & $\mathrm{P}$ & $\mathrm{W}$ & $\mathrm{D}$ & $\mathrm{C}$ & $\mathrm{P}$ & $\mathrm{W}$ & $\mathrm{D}$ & $\mathrm{C}$ & $\mathrm{P}$ \\
\hline Option 1 & 0 & 0 & 0 & 1 & 0 & 0 & 0 & 1 & 0 & 0 & 0 & 1 & 0 & 0 & 0 & 1 \\
\hline Option 2 & 0 & 0 & 1 & 0 & 0 & 0 & 1 & 0 & 0 & 0 & 1 & 0 & 0 & 0 & 1 & 0 \\
\hline Option 3 & 0 & 0 & 1 & 1 & 0 & 0 & 1 & 1 & 0 & 0 & 1 & 1 & 0 & 0 & 1 & 1 \\
\hline Option 4 & 0 & 1 & 0 & 0 & 0 & 1 & 0 & 0 & 0 & 1 & 0 & 0 & 0 & 1 & 0 & 0 \\
\hline Option 5 & 0 & 1 & 0 & 1 & 0 & 1 & 0 & 1 & 0 & 1 & 0 & 1 & 0 & 1 & 0 & 1 \\
\hline Option 6 & 0 & 1 & 1 & 0 & 0 & 1 & 1 & 0 & 0 & 1 & 1 & 0 & 0 & 1 & 1 & 0 \\
\hline Option 7 & 0 & 1 & 1 & 1 & 0 & 1 & 1 & 1 & 0 & 1 & 1 & 1 & 0 & 1 & 1 & 1 \\
\hline Option 8 & 1 & 0 & 0 & 0 & 1 & 0 & 0 & 0 & 1 & 0 & 0 & 0 & 1 & 0 & 0 & 0 \\
\hline Option 9 & 1 & 0 & 0 & 1 & 1 & 0 & 0 & 1 & 1 & 0 & 0 & 1 & 1 & 0 & 0 & 1 \\
\hline Option 10 & 1 & 0 & 1 & 0 & 1 & 0 & 1 & 0 & 1 & 0 & 1 & 0 & 1 & 0 & 1 & 0 \\
\hline Option 11 & 1 & 0 & 1 & 1 & 1 & 0 & 1 & 1 & 1 & 0 & 1 & 1 & 1 & 0 & 1 & 1 \\
\hline Option 12 & 1 & 1 & 0 & 0 & 1 & 1 & 0 & 0 & 1 & 1 & 0 & 0 & 1 & 1 & 0 & 0 \\
\hline Option 13 & 1 & 1 & 0 & 1 & 1 & 1 & 0 & 1 & 1 & 1 & 0 & 1 & 1 & 1 & 0 & 1 \\
\hline Option 14 & 1 & 1 & 1 & 0 & 1 & 1 & 1 & 0 & 1 & 1 & 1 & 0 & 1 & 1 & 1 & 0 \\
\hline Option 15 & 1 & 1 & 1 & 1 & 1 & 1 & 1 & 1 & 1 & 1 & 1 & 1 & 1 & 1 & 1 & 1 \\
\hline
\end{tabular}

$W=$ wet storage (SFPI), $\mathrm{D}=$ dry storage (ISFSI), $C=\mathrm{CDS}$, and $P=\mathrm{PDF}$.

TABLE 13: Converted $(\mathrm{ON}=1$ and $\mathrm{OFF}=0)$ operation mode options with total cost values of facilities (million USD) in the Barakah site.

\begin{tabular}{lccccc}
\hline & \multicolumn{5}{c}{ Operation mode } \\
Options & Barakah-1 & Barakah-2 & Barakah-3 & Barakah-4 & Total \\
\hline Option 1 & 501.0 & 501.0 & 501.0 & 501.0 & 2004.0 \\
Option 2 & 427.1 & 427.1 & 427.1 & 427.1 & 1708.4 \\
Option 3 & 928.1 & 928.1 & 928.1 & 928.1 & 3712.4 \\
Option 4 & 501.0 & 501.0 & 501.0 & 501.0 & 2004.0 \\
Option 5 & 537.9 & 537.9 & 537.9 & 537.9 & 2151.4 \\
Option 6 & 464.0 & 464.0 & 464.0 & 464.0 & 1855.8 \\
Option 7 & 965.0 & 965.0 & 965.0 & 965.0 & 3859.8 \\
Option 8 & 16.9 & 16.9 & 16.9 & 16.9 & 67.8 \\
Option 9 & 517.9 & 517.9 & 517.9 & 517.9 & 2071.8 \\
Option 10 & 444.1 & 444.1 & 444.1 & 444.1 & 1776.2 \\
Option 11 & 945.0 & 945.0 & 945.0 & 945.0 & 3780.2 \\
Option 12 & 53.8 & 53.8 & 53.8 & 53.8 & 215.2 \\
Option 13 & 554. & 554. & 554. & 554. & 2219.2 \\
Option 14 & 480.9 & 480.9 & 480.9 & 480.9 & 1923.6 \\
Option 15 & 981.9 & 981.9 & 981.9 & 981.9 & 3927.6 \\
\hline
\end{tabular}

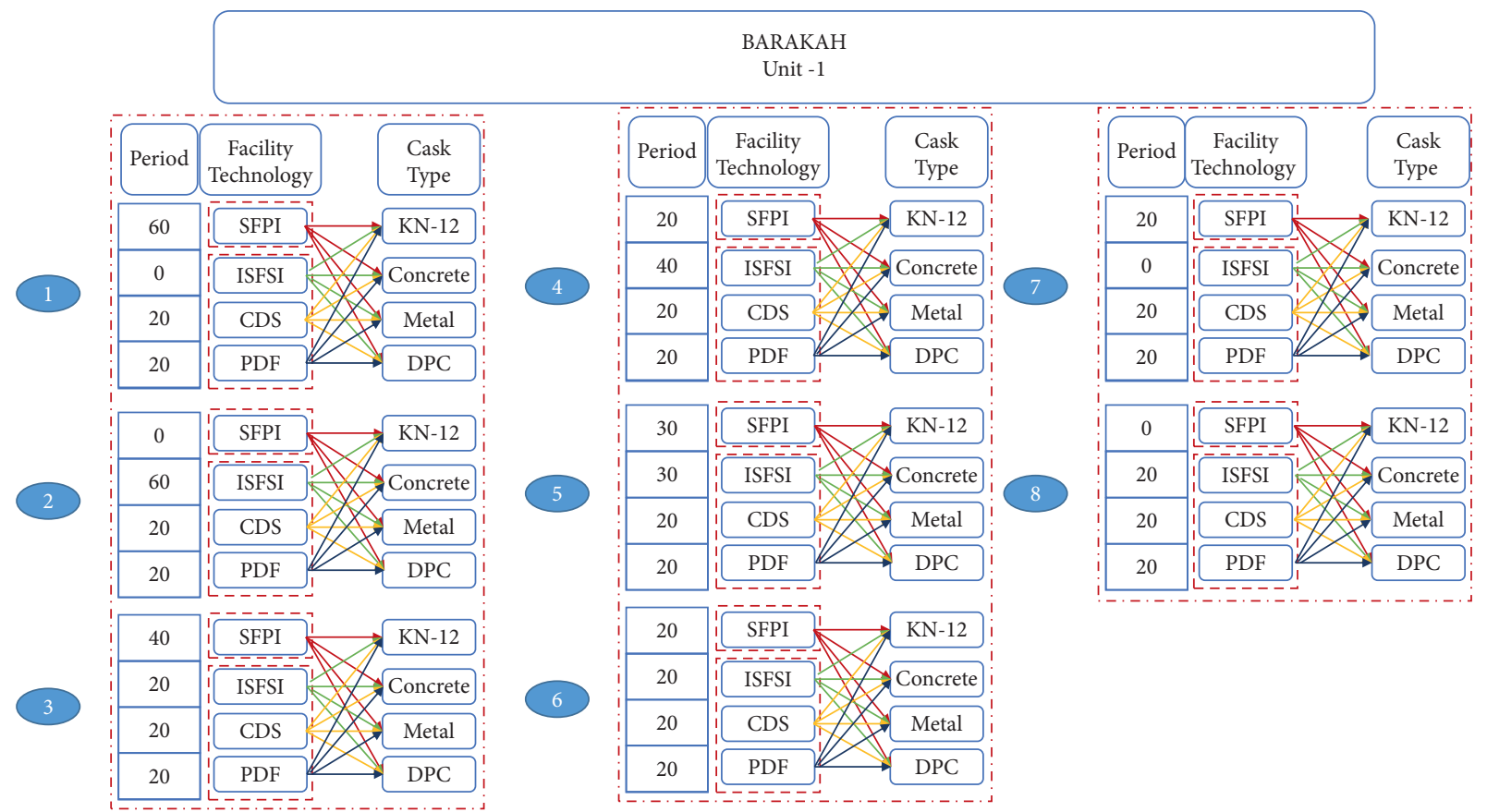

FIgURE 6: Overall operation-mode scenarios for spent fuel management in Barakah unit 1. 


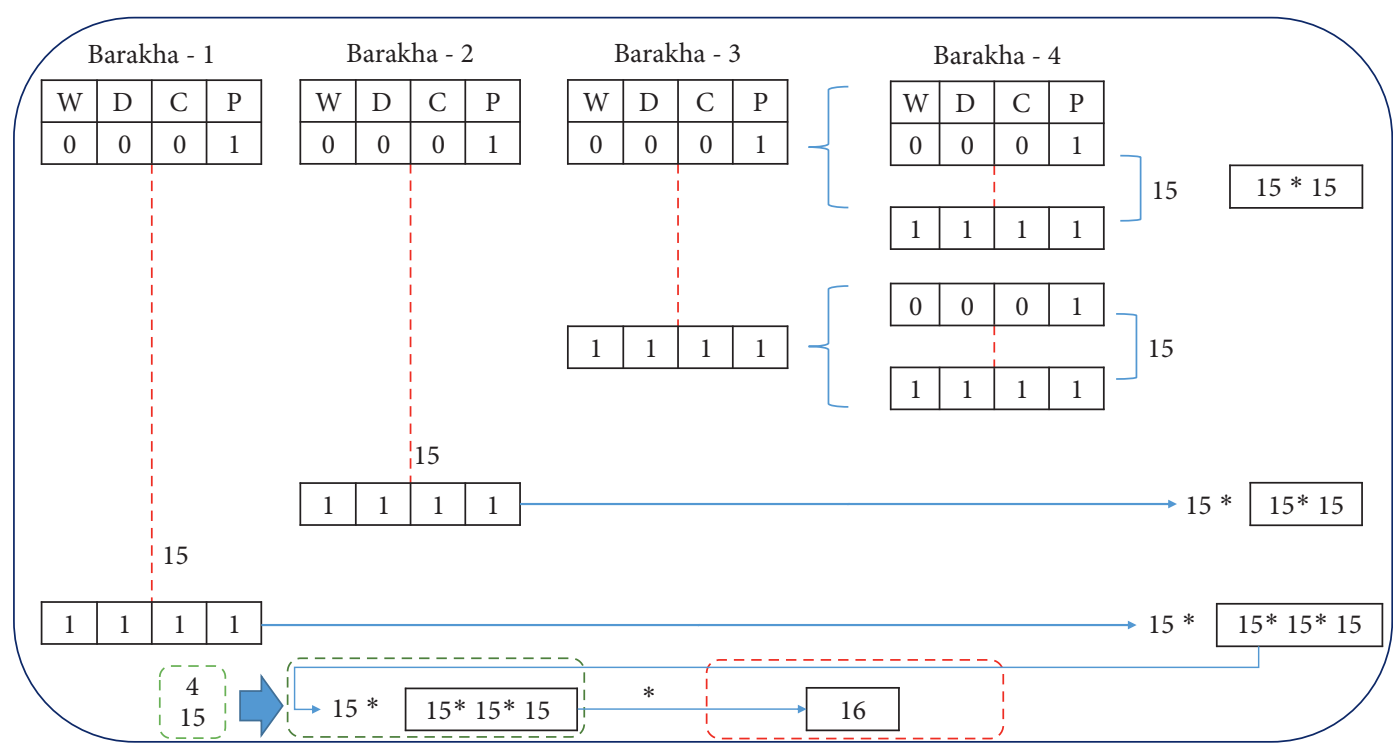

Figure 7: In-house MATLAB schematic tool for generating the switching operation-mode probability matrix.

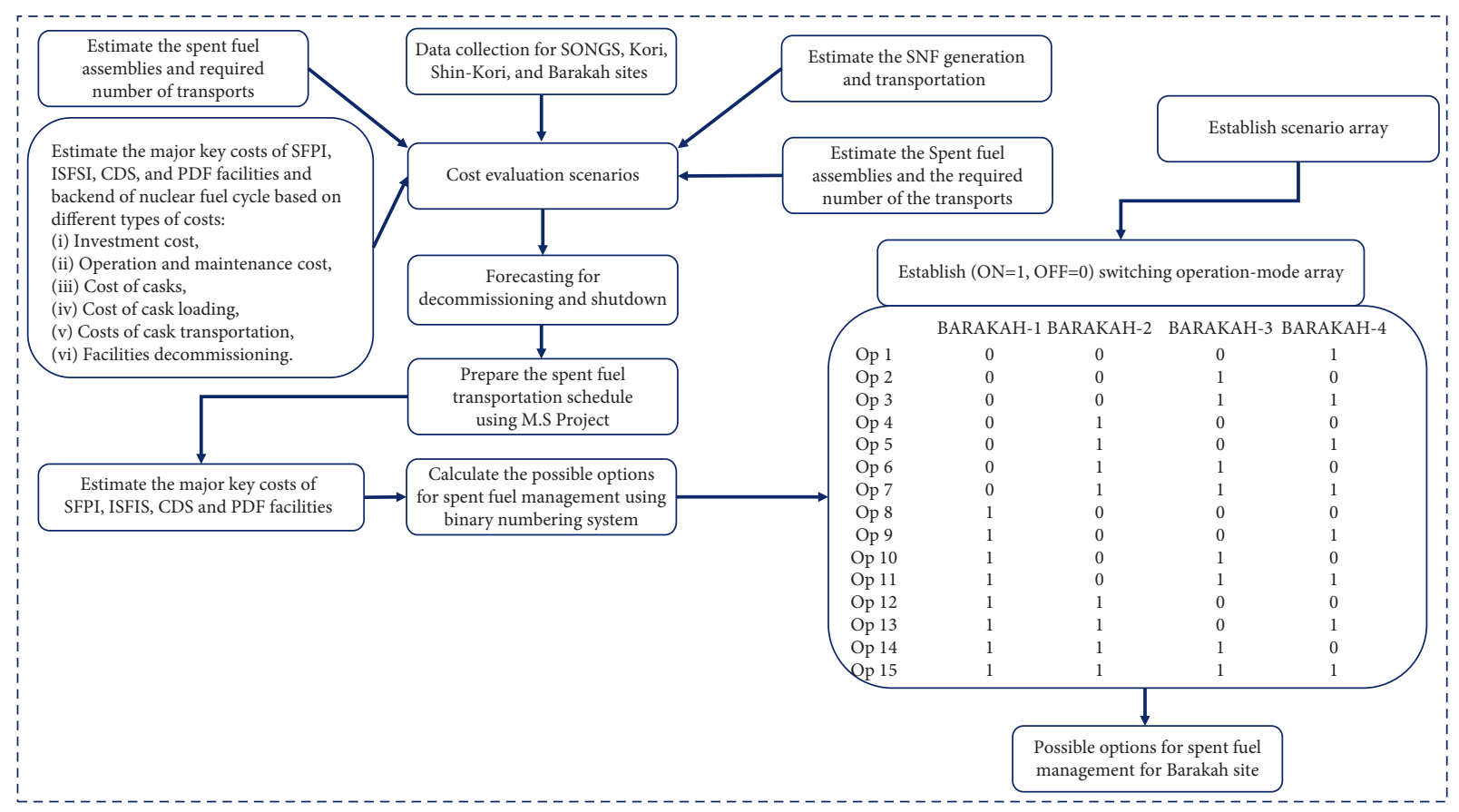

Figure 8: Overall procedure for spent fuel management for Barakah site.

TABLE 14: Summary of total cost (M USD) per cost category.

\begin{tabular}{lcccccccc}
\hline Items cost & Sc-1 & Sc-2 & Sc-3 & Sc-4 & Sc-5 & Sc-6 & Sc-7 & Sc-8 \\
\hline Investments & 2413.8 & 2413.8 & 2297.8 & 2330.3 & 2094.4 & 2184.5 & 1962.3 & 2023.1 \\
O\&M & 856.9 & 869.8 & 860.2 & 863.3 & 861.0 & 856.0 & 845.6 & 850.0 \\
Decommissioning & 772.0 & 793.8 & 903.2 & 781.2 & 776.3 & 759.4 & 726.0 & 862.0 \\
Casks storage & 327.3 & 327.3 & 250.9 & 250.9 & 192.3 & 113.0 & 113.0 & 113.0 \\
Casks loading & 203.4 & 203.4 & 197.5 & 197.5 & 194.7 & 176.5 & 146.6 & 146.6 \\
Transportation & 513.5 & 729.7 & 588.1 & 588.1 & 610.8 & 588.1 & 513.5 & 588.1 \\
Total & 5086.8 & 5337.8 & 5097.6 & 5011.4 & 4729.6 & 4677.4 & 4306.9 & 4582.7 \\
\hline
\end{tabular}


TABLE 15: Summary of total cost (M USD) per facility storage technology.

\begin{tabular}{lcccccccc}
\hline Facility & Sc-1 & Sc-2 & Sc-3 & Sc-4 & Sc-5 & Sc-6 & Sc-7 & Sc-8 \\
\hline SFPI & 769.7 & 216.3 & 441.5 & 290.1 & 175.8 & 290.1 & 215.5 & 74.6 \\
ISFSI & 584.1 & 1375.5 & 919.8 & 981.8 & 816.6 & 655.1 & 369.7 & 781.9 \\
CDS & 1514.5 & 1514.5 & 1514.5 & 1514.5 & 1514.5 & 1514.5 & 1514.5 & 1514.5 \\
PDF & 1875.1 & 2091.4 & 1949.8 & 1949.8 & 1972.5 & 1949.8 & 1875.1 & 1949.8 \\
Total & 4743.4 & 5197.7 & 4825.6 & 4736.2 & 4479.4 & 4409.5 & 3974.8 & 4320.8 \\
\hline
\end{tabular}

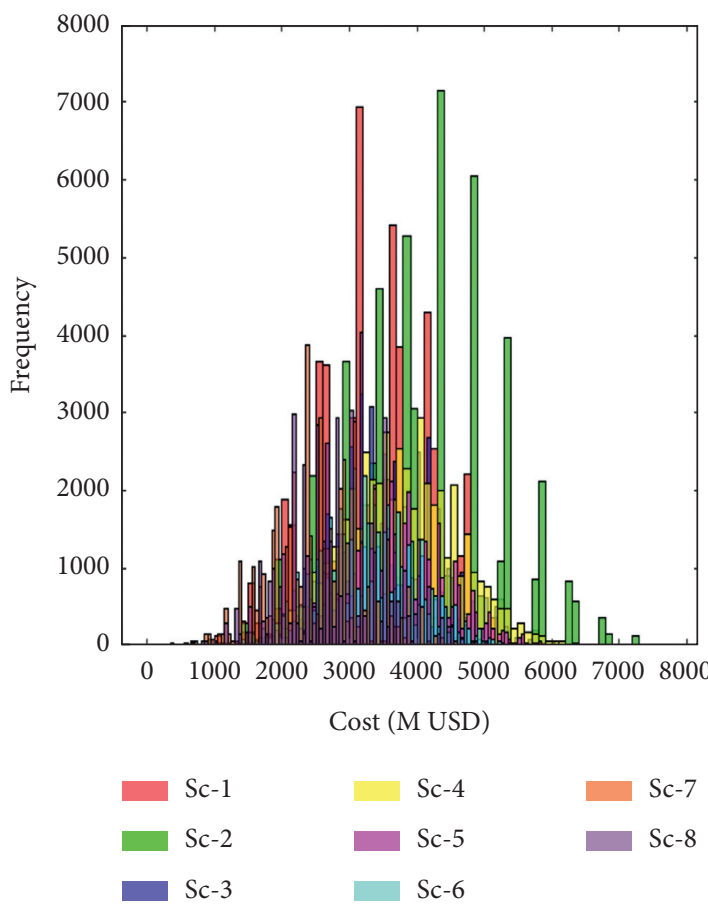

(a)

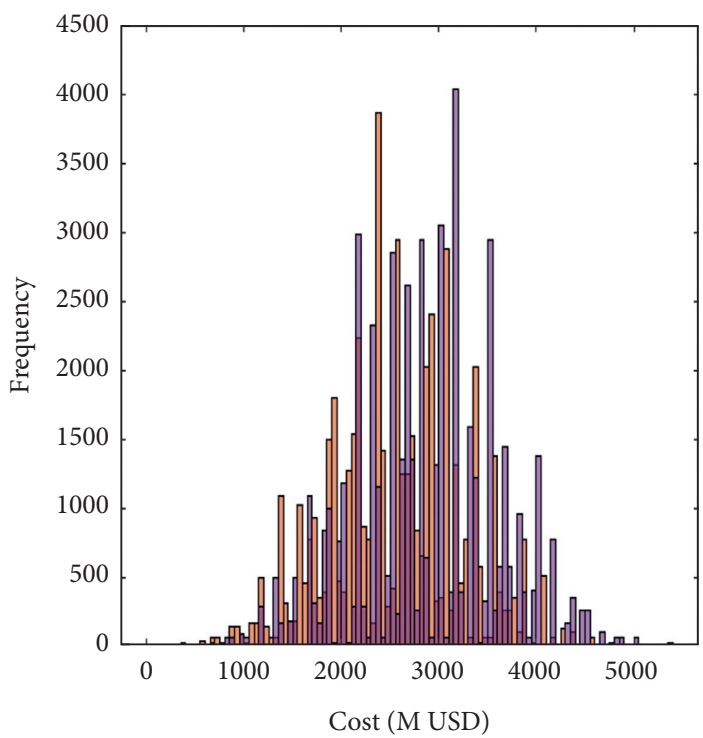

Sc-7

Sc-8

(b)

FIgURE 9: MATLAB simulations for case (a) and (b).
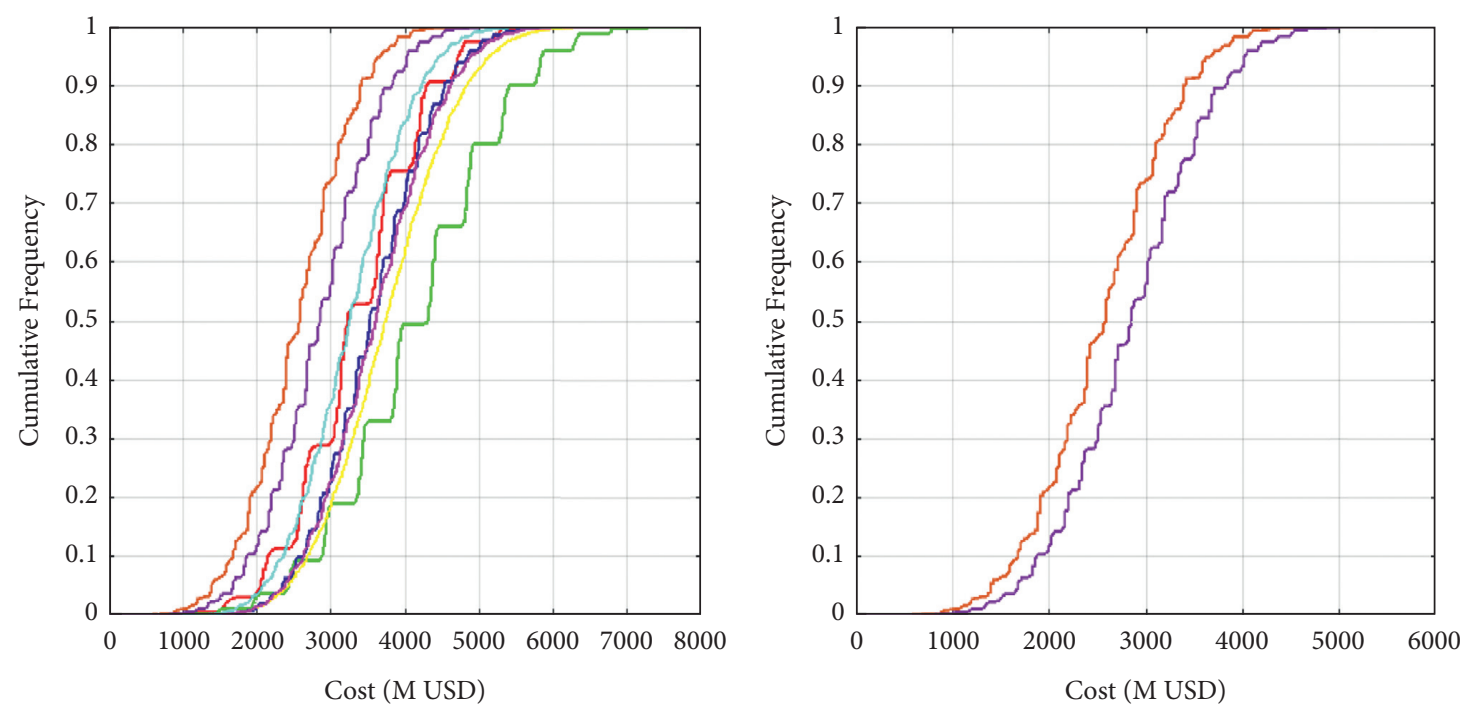

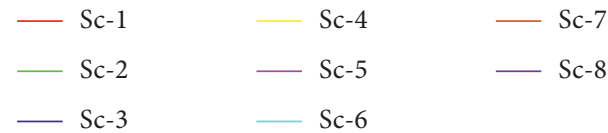

(a) (b)

Figure 10: MATLAB simulations of cost versus cumulative frequency (a) for all scenarios and (b) for Sc-7 \& Sc-8. 


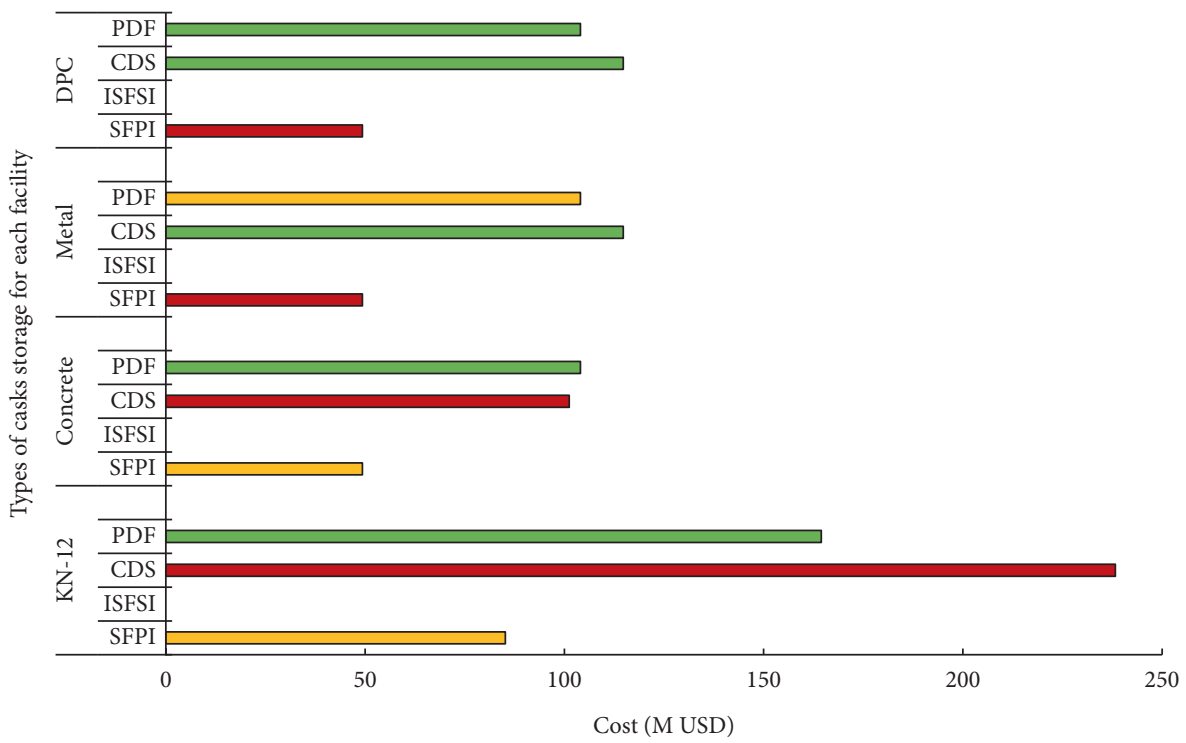

FiguRE 11: Breakdown of costs for each facility storage utilizing different types of cask storage.

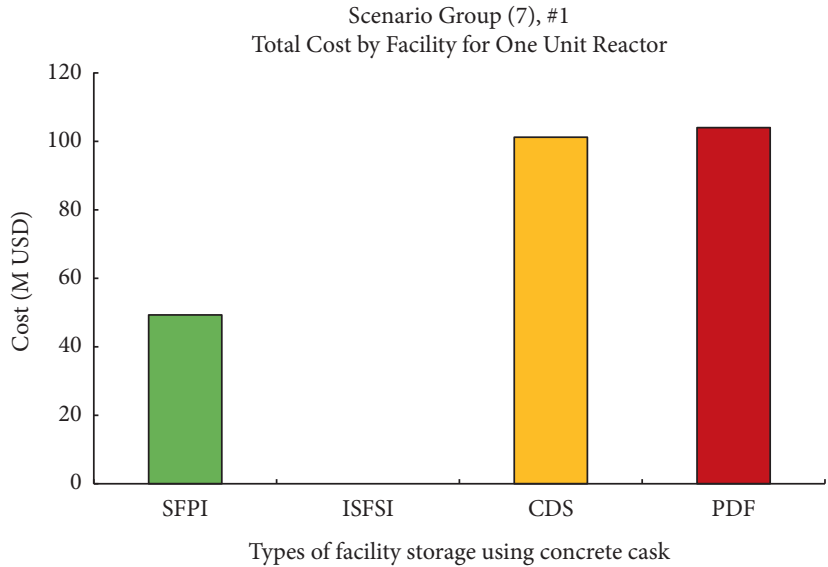

FIGURE 12: Breakdown of costs for all facility storages utilizing concrete casks.

$40.7 \%, 41.0 \%, 42.7 \%$, and $47.9 \%$, respectively, for the decommissioning cost. By contrast, the other cost categories, such as the relevant costs for cask storage and cask loading, will exhibit lower shares compared to those of the decommissioning and O\&M cost categories. The relevant costs for cask storage will reach $6.2 \%, 8.8 \%, 5.1 \%, 12.2 \%$, and $10.6 \%$, respectively, whereas the relevant costs for cask loading will reach $4.1 \%, 5.0 \%, 11.6 \%, 5.3 \%$, and $6.1 \%$, respectively.

Based on the thus designed parameters for Sc-7, the SNF will be transported to the SFPI facility 20 years after the start of the shutdown of the reactor, with the 7-year SNF transition and cooling period taken into account. Therefore, the SFPI is expected to start operating by 2040. After 20 years, the SNF will then be transferred to a CDS or PDF facility, which is expected to start operating by 2060. The Barakah site is projected to be completely shut down by 2080. The schedule of these processes is shown in Figure 17.
To show the effect of changes in investment cost, specifically the variable-cost investment on the total cost of the storage system, a sensitivity analysis was performed with reductions in the variable cost of the CDS facility, as shown in Table 9, from 1.41 million USD/cask, as in Spain, to 0.462 million USD/cask, as in the US. As shown in Figures 18(a) and 18 (b) and 19(a) and 19(b), Sc-8 becomes the most costeffective among the tested scenarios, followed by Sc-7.

As shown in Figure 14, the investment cost had the highest share among the cost categories; therefore, it is important to show the direct effect of reducing the investment cost, specifically the variable cost of the CDS facility for the storage system. Figures 20 and 21 show this effect in detail on the total cost per cost category for Sc-8. The calculation for Sc-8 considered only the ISFSI and CDS facilities, and thus the scenario is to be represented by 0-20-200, instead of by 0-20-20-20, as shown in Figure 20.

Figures 21(a) and 21(b) show the effect of changing the investment cost, specifically the variable cost, on the ranking 


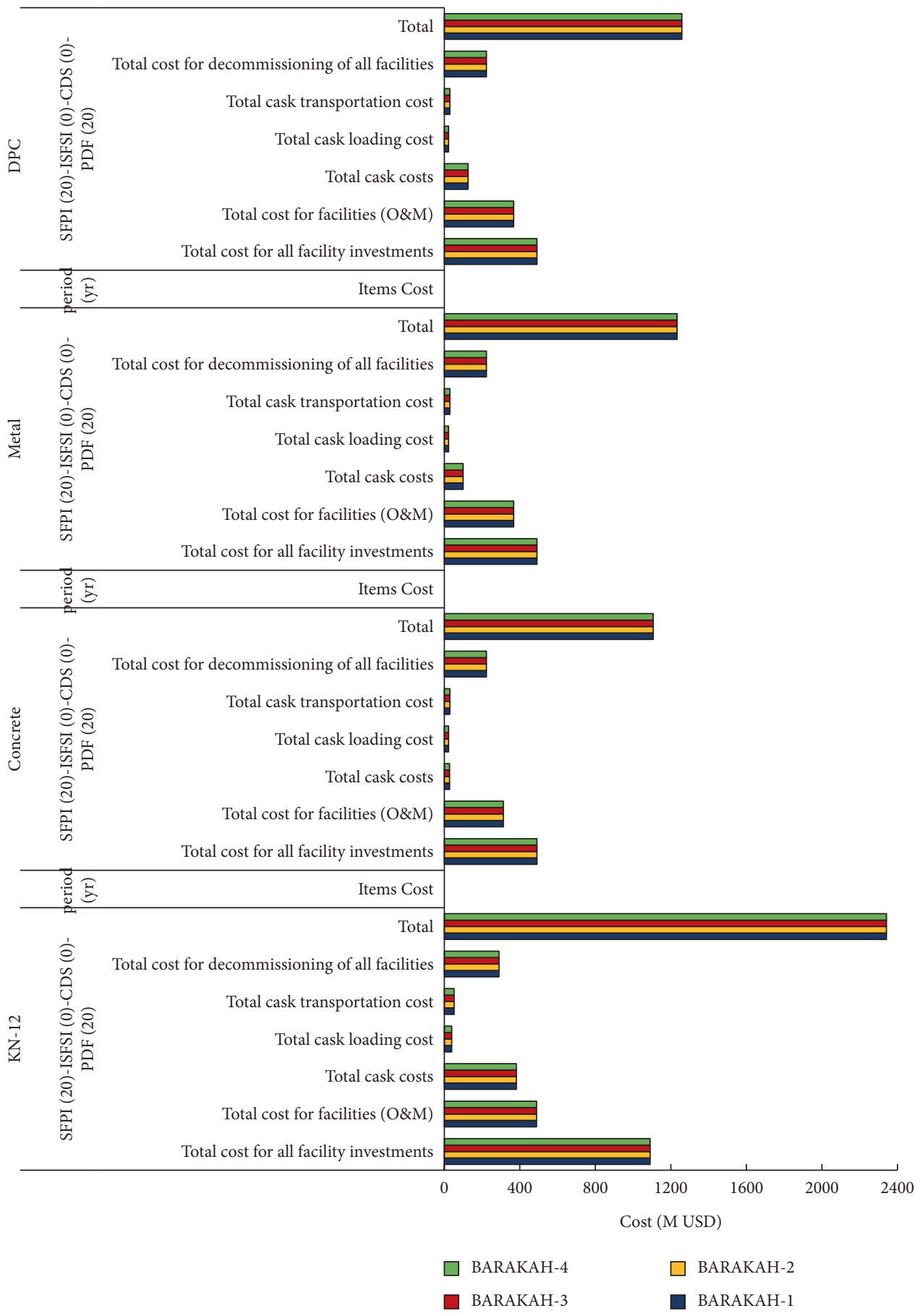

FIgURE 13: Total cost per cost category for different types of cask storage, for Sc-7 of Barakah site.

priority of the storage system for two cases. In the first case, wherein the cost was 1.41 million USD/cask, as in Spain (a), Sc-7 was the best option for the storage system. On the other hand, in the second case, when the variable cost was reduced to 0.462 million USD/cask, as in the US (b), Sc- 8 became the best option for the storage system. These savings are due to the investment cost being the highest cost contributor among the cost categories, accounting for almost 39\% to $42 \%$ of the total cost of any storage system, as shown in Figure 14. Reductions in the variable investment cost resulted in reductions of $37.1 \%, 28.1 \%, 36.1 \%, 37.8 \%, 39.5 \%$, $40.2 \%, 45.5 \%$, and $23.5 \%$ in the total cost of the storage system for Sc-1, Sc-2, Sc-3, Sc- 4\%, Sc-5, Sc-6, Sc-7, and Sc-8, respectively. Among these, the most affected scenario was Sc-7, which underwent a cost reduction of approximately $45.5 \%$.

Moreover, the aforementioned results are comparable in range to the storage system costs determined in previous studies, as shown in Figure 22. In the low range, the cost determined in our study, i.e., 2,000 million USD, is higher 


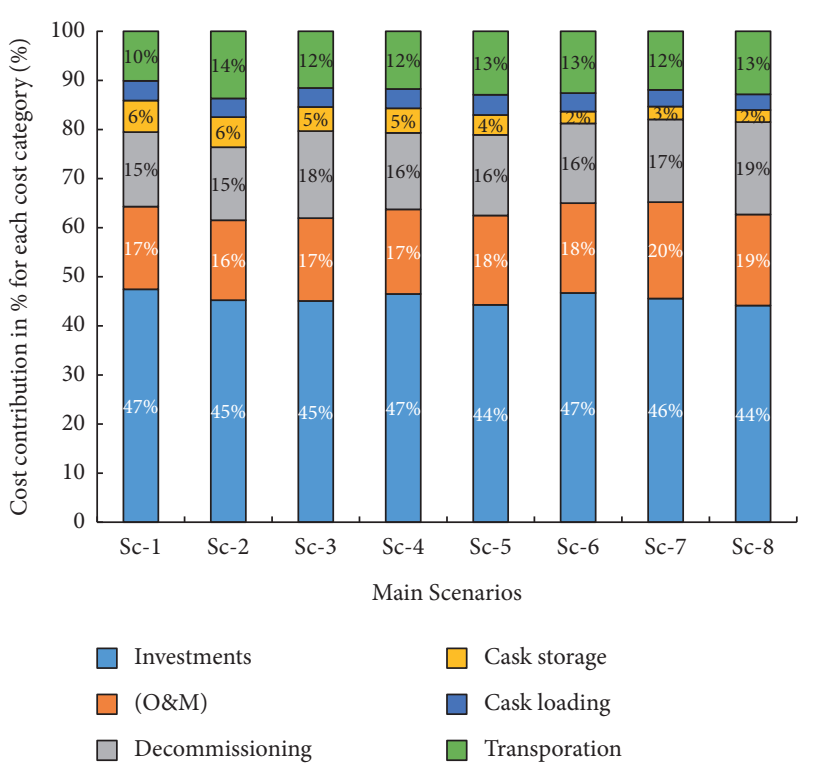

FIgURE 14: Cost contribution per cost category in \% of total cost for each scenario.

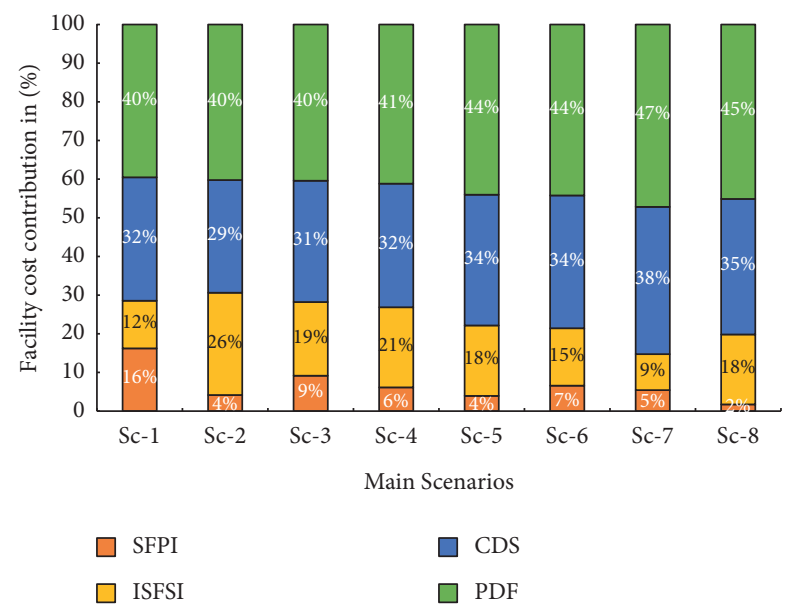

FIGURE 15: Cost contribution per facility storage technology in \% of total cost for each scenario.

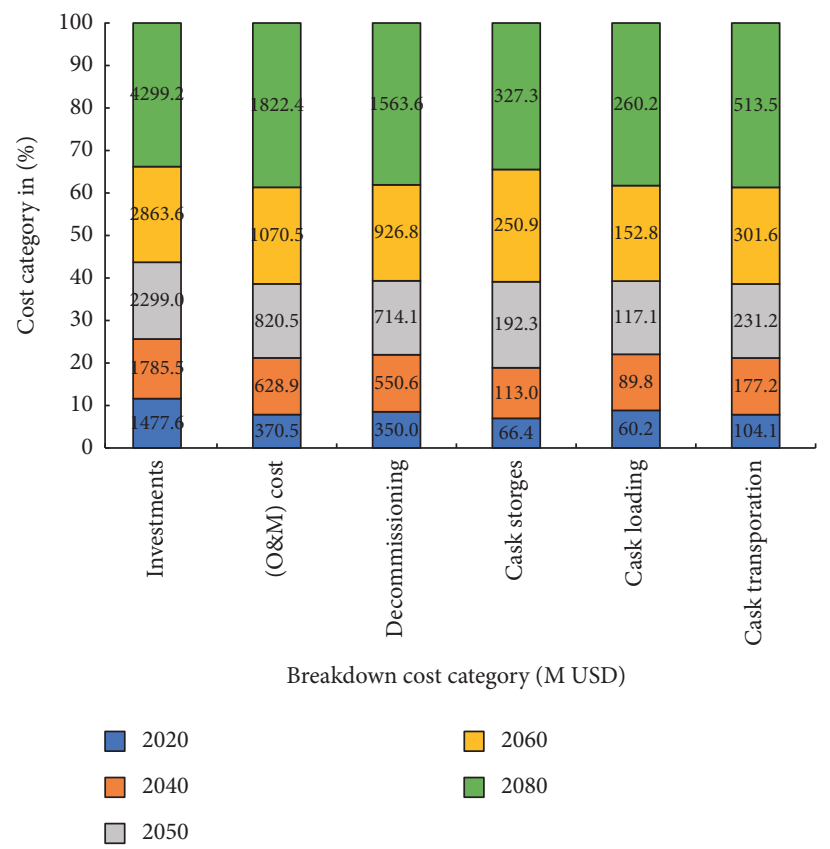

Figure 16: Breakdown of cost categories in \% of total cost for facilities using concrete cask storages, for Sc-7. 


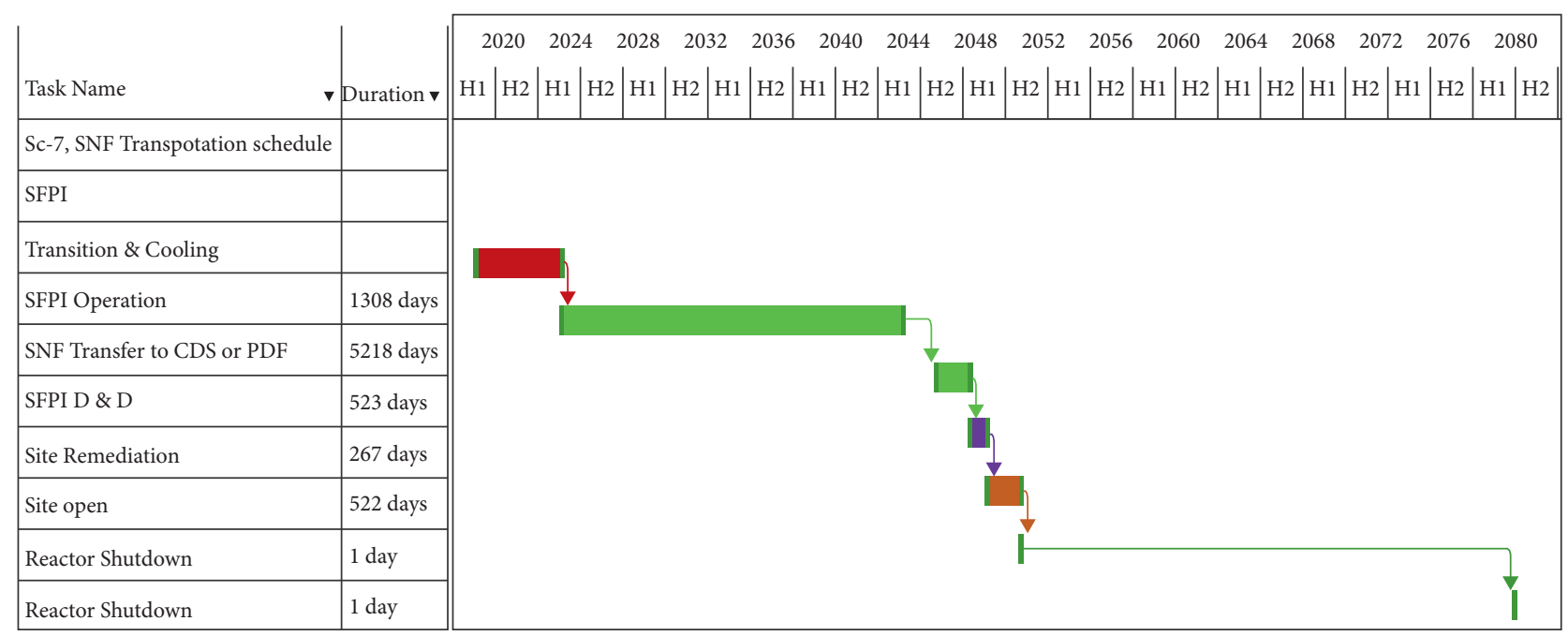

FIGURE 17: Sc-7 SNF transportation schedule to storage facilities.

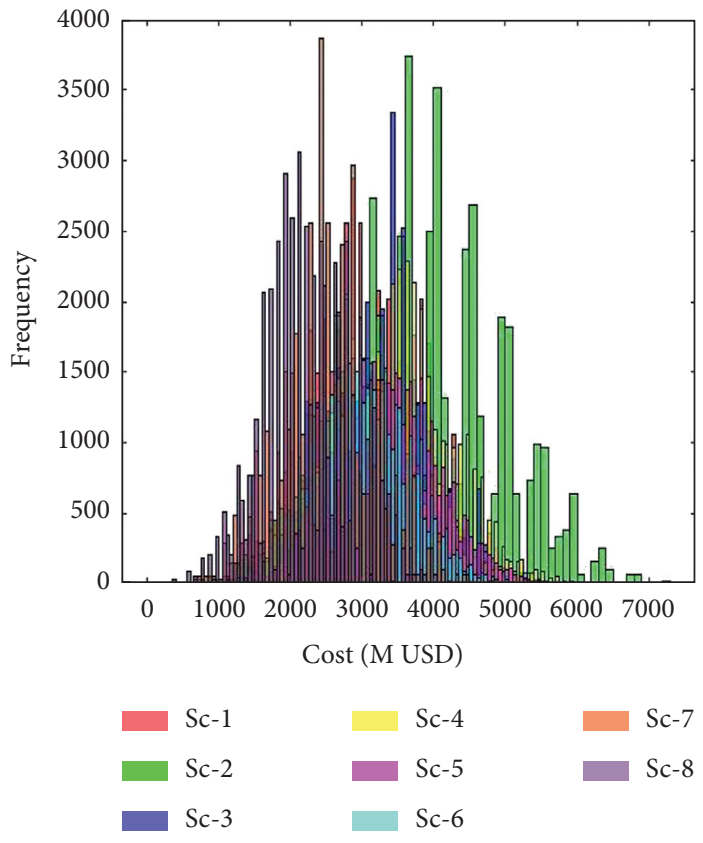

(a)

Figure 18: Continued. 


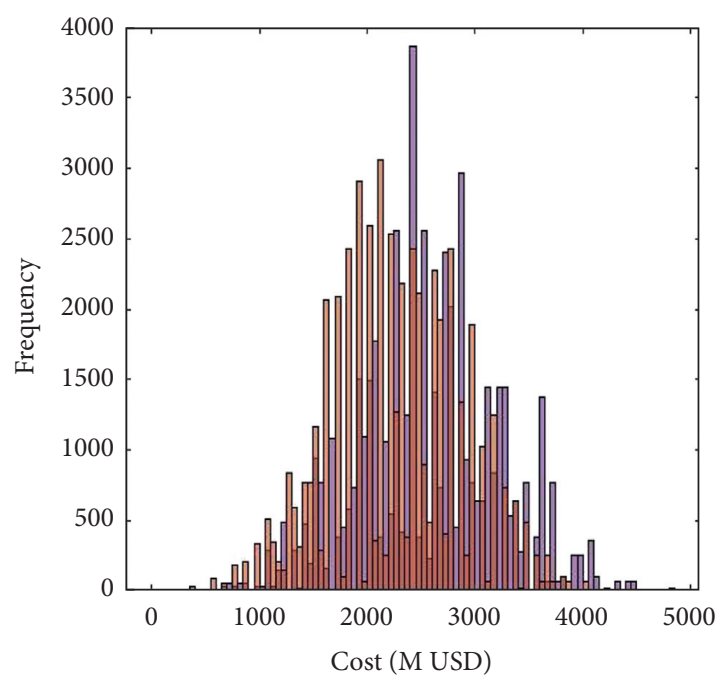

Sc-7

Sc- 8

(b)

Figure 18: MATLAB simulations for case (a) and (b).

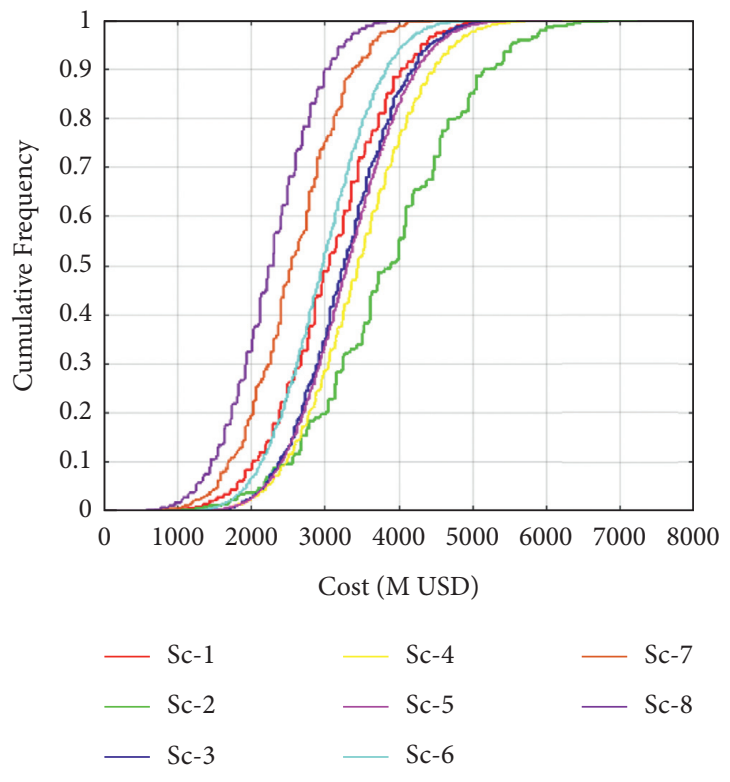

(a)

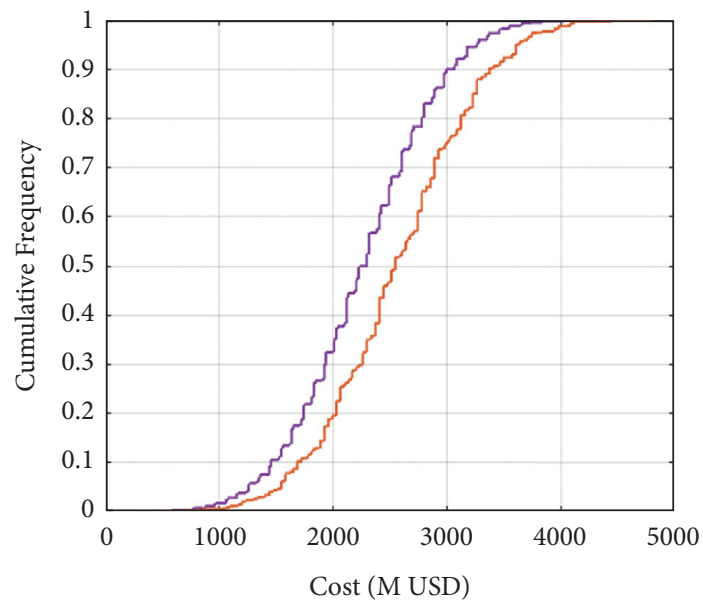

— Sc-7

- Sc-8

Figure 19: MATLAB simulations of cost versus cumulative frequency (a) for all scenarios and (b) for Sc-7 \& Sc-8. 


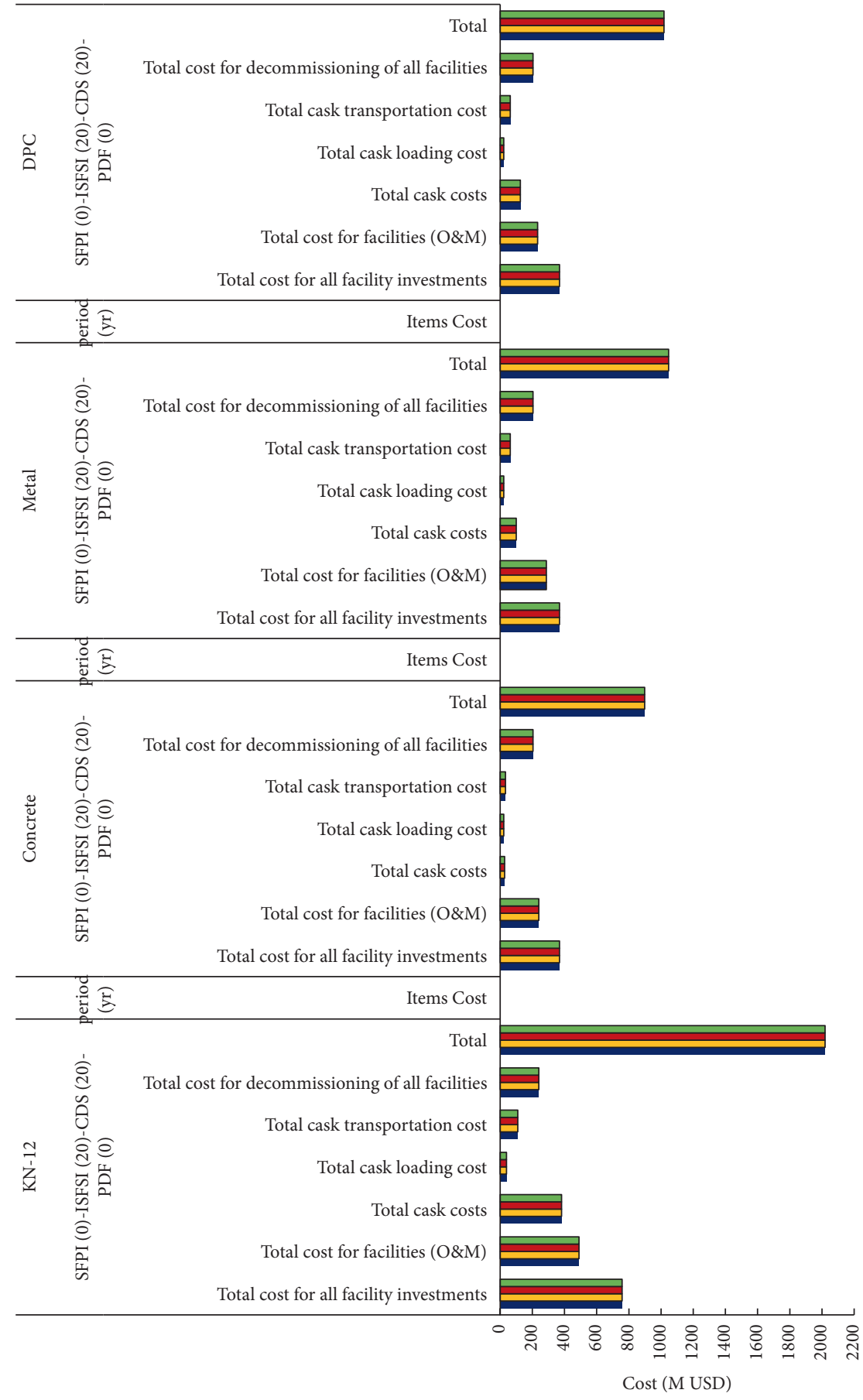

$\square$ BARAKAH-4 $\square$ BARAKAH-2

$\square$ BARAKAH-3 $\square$ BARAKAH-1

FIgURE 20: Total cost per cost category for different types of cask storage, for Sc-8 of Barakah site. 


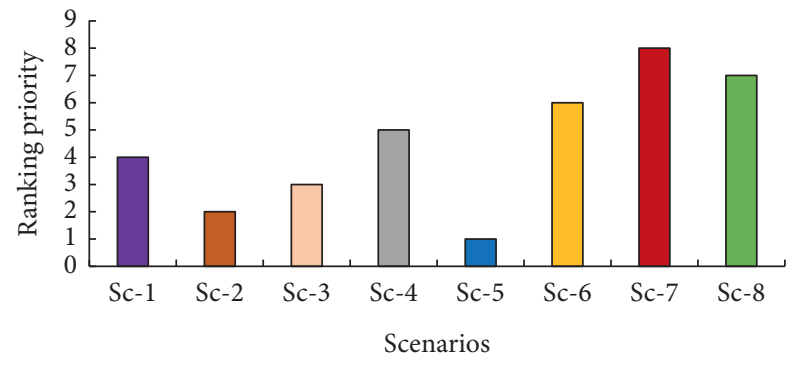

(a)

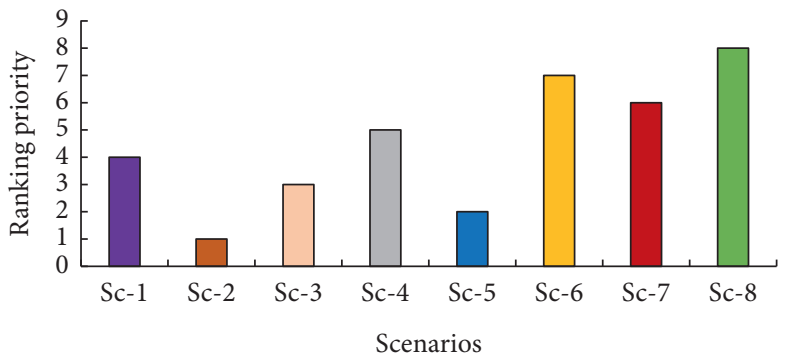

(b)

FIGURE 21: Ranking priority for eight main scenarios with different variable investment costs.

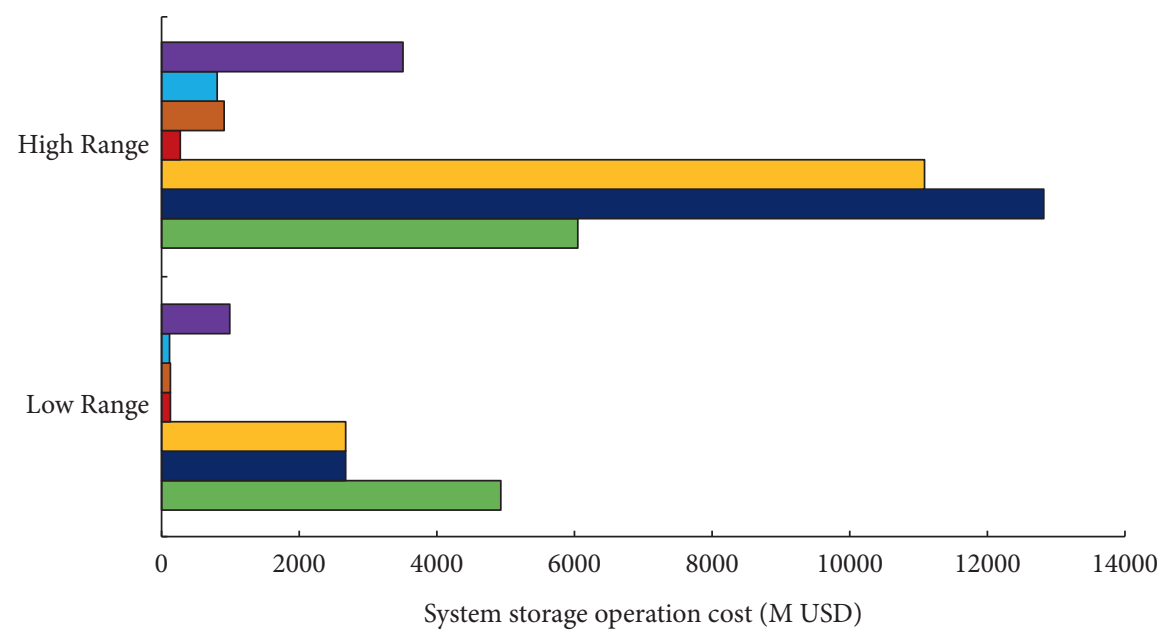
G. Aubert [28]
L. R. Penalonga [5]
S. Maxwell [50]
L. R. Penalonga [31]
W.S. Hyung [51]
This case study
S. Al Saadi [3]

Figure 22: Comparison of storage system total cost with those of other studies.

TABle 16: Summarized comparison with other case studies.

\begin{tabular}{|c|c|c|c|c|c|c|}
\hline & Reference year & Inflation rate & Escalated rate & Discount rate & No. of operation options & Cost category \\
\hline This case study & 2020 & 1.2 & 3 & 1.5 & 15 & 6 \\
\hline Al Saadi [3] & 2014 & $\mathrm{NC}^{*}$ & $\mathrm{NC}^{*}$ & $5 \%$ & 2 & 2 \\
\hline Penalonga [5] & 2017 & $\mathrm{NC}^{*}$ & $\mathrm{NC}^{*}$ & 1.5 & 4 & 6 \\
\hline Aubert [28] & 2005 & 2 & $\mathrm{NC}^{*}$ & 3 & 2 & 5 \\
\hline Penalonga [31] & 2017 & $\mathrm{NC}^{*}$ & $\mathrm{NC}^{*}$ & 1.5 & 4 & 6 \\
\hline Maxwell [50] & 2017 & 2 & 3 & 2.1 & 4 & 4 \\
\hline Hyung [51] & 2014 & $\mathrm{NC}^{*}$ & $\mathrm{NC}^{*}$ & $\mathrm{NC}^{*}$ & 8 & 5 \\
\hline
\end{tabular}

$\mathrm{NC}^{*}$ : not considered.

than those reported by other studies. On the other hand, in the high range, the cost determined in our study is within the high ranges reported by the other studies, because of the use of variations in the economic parameters [3, 5, 28, 31, 50, 51].

This study resulted in a wide range of mode-of-operation options, i.e., 15 options, which include six cost categories. By comparison, other methods involve only two and eight modes of operation options with four and six cost categories $[50,51]$. The factor that made our work preferable to the others is that most past studies, to the best of our knowledge, did not include the economic parameters outlined in Tables 8 and 9. For example, a number of studies did not include the inflation and escalation rate $[3,51]$. Nonetheless, another study that involved fewer options resulted in cost ranges that were comparable to those calculated in our case study, perhaps because of differences in the time periods that were used [50]. A summarized comparison with the other case studies is presented in Table 16. 


\section{Conclusions}

Spent fuel management will be one of the most important priorities of the UAE for its nuclear power plants after their permanent shutdown and subsequent discharge of spent nuclear fuel, specifically from the Barakah site. The UAE can initially store the spent nuclear fuel discharged from the Barakah nuclear power plants using a spent fuel pool system, after which the SNF can be transferred to a dry storage facility, where the spent fuel can be stored for 20 to 100 years. We evaluated eight main scenarios to determine the optimal option, from an economic and technical point of view, for managing the SNF. We applied the net present value and used the MS Project and MATLAB software programs to calculate the total cost for each storage system scenario.

The results revealed the optimal strategy for the UAE, identified in this paper as Sc-7. In this scenario, a (wet) spent fuel pool island, i.e., SFPI storage facility, is operated after the first 20 years of the reactor shutdown, and then the spent fuel is transferred after 20 years directly to a permanent disposal facility (PDF). Compared to the other options, this scenario results in a $20.9 \%$ to $26.1 \%$ reduction in the total cost, and costs approximately 4,307 million USD.

The cost contribution per unit cost category shows that the investment cost is the highest cost contributor among the cost categories. The investment cost accounts for approximately $44 \%$ to $47 \%$ of the total cost. The results also showed that the SFPI has the lowest cost contribution compared with the other storage facilities; it has a cost range of approximately $2 \%$ to $16 \%$. The SFPI is followed by the ISFSI and CDS, with cost contributions ranging from $10 \%$ to $28 \%$, and from $28 \%$ to $38 \%$, respectively. Meanwhile, the PDF facility has the highest cost contribution, starting from $40 \%$ to $47 \%$.

The breakdown of the cost category shows that, from 2020 to 2080, there will be escalations in the investment cost, O\&M cost, decommissioning cost, cask storage cost, cask loading cost, and cask transportation cost. The costs for the O\&M and decommissioning cost categories that are relevant to the investment cost are visualized via the height share and compared with other cost categories for the following years: 2020, 2040, 2050, 2060, and 2080. The other cost categories, such as the relevant costs for cask storage and cask loading, exhibit lower shares compared to those of the decommissioning and O\&M cost categories.

The results show that concrete cask storage is the cheapest option among the types of casks examined in this study, and that changing the period time for facility of storage will cause changes in the storage system priority. In addition, a strategy involving 20 years of storage in an SFPI storage system is the best time-period option; after 20 years, the SNF moves directly to a permanent disposal facility storage. Consequently, this option will reduce the total cost of the storage system strategy.

The variable investment costs have a significant effect on the total cost of the storage system and can influence the strategy in terms of the storage facility and path that is used. Based on the aforementioned results and overall conclusion, we determined that a strategy of applying a centralized dry storage is not economical as a storage system strategy for a long time, i.e., at least 20 years (unless the variable investment cost is reduced or changed). Therefore, we recommend transferring the spent nuclear fuel to a permanent disposal facility after it is stored for 20 years in a centralized interim storage system. This is because the total cost of a permanent disposal facility is lower than that of a centralized dry storage system for nuclear power plants in the UAE.

\section{Data Availability}

The data used to support the study findings have been included in the article.

\section{Conflicts of Interest}

The authors declare no conflicts of interest.

\section{Acknowledgments}

This work was supported by Korea Institute of Energy Technology Evaluation and Planning (KETEP) grant funded by the Korea government (MOTIE) (no. 20203210100240, Development of a platform for Optimization of Interdependences in Packaging-Transport-Disposal of Radioactive Waste and History Management).

\section{References}

[1] M. Al-Saidi and M. Haghirian, "A quest for the Arabian atom? geopolitics, security, and national identity in the nuclear energy programs in the Middle East," Energy Research \& Social Science, vol. 69, Article ID 101582, 2020.

[2] Unit 1 of UAE's Barakah NPP Begins Operation, "Nuclear engineering international magazine (NEIM)," 2020, https:// www.neimagazine.com/news/newsunit-1-of-uaes-barakahnpp-begins-operation-8059099.

[3] S. Al Saadi and Y. Yi, "Interim storage of spent nuclear fuel in the UAE nuclear power plants,"” in Proceedings of the 2nd International Conference on Nuclear Engineering, Prague, Czech Republic, June 2014.

[4] IAEA, "Nuclear power and its fuel cycle expansion planning for electrical generating systems," in International Atomic Energy Agency, A GuidebookIAEA, Vienna, Austria, 1984.

[5] L. Moratilla Soria and B. Y. M. Soria, "A proper spent nuclear fuel management strategy could enhance the continuity of nuclear power in the Spanish energy mix," International Journal of Energy Research, vol. 45, no. 1, pp. 269-282, 2020.

[6] V. S. Krasnorutskij and O. S. Kirsanova, "On the options of Ukraine's nuclear fuel cycle," Problems of Atomic Science and Technology, vol. 2, pp. 74-81, 2019, https://inis.iaea.org/ search/searchsinglerecord.aspx? recordsFor=SingleRecord\&R $\mathrm{N}=50046519$.

[7] Y. Chen, G. Martin, C. Chabert, R. Eschbach, H. He, and G.-a. Ye, "Prospects in China for nuclear development up to 2050," Progress in Nuclear Energy, vol. 103, pp. 81-90, 2018, https://hal-cea.archives-ouvertes.fr/cea-01908268/document.

[8] Q. Yue, J. He, S. Zhi, and H. Dong, "Fuel cycles optimization of nuclear power industry in China," Annals of Nuclear Energy, vol. 111, pp. 635-643, 2018.

[9] J.-P. Zhang, Z.-R. Liu, and L. Wang, "Uranium demand and economic analysis of different nuclear fuel cycles in China," Energy Strategy Reviews, vol. 9, pp. 50-61, 2016. 
[10] R. Gao, S. Choi, Y. Zhou, and W. II Ko, "Performance modeling and analysis of spent nuclear fuel recycling," International Journal of Energy Research, vol. 39, no. 15, pp. 1981-1993, 2015.

[11] S. K. Kim, W. I. Ko, S. R. Youn, and R. X. Gao, "Nuclear fuel cycle cost estimation and sensitivity analysis of unit costs on the basis of an equilibrium model," Nuclear Engineering and Technology, vol. 47, no. 3, pp. 306-314, 2015.

[12] S. Kim, W. Ko, S. Youn, R. Gao, and S. Bang, "Advanced fuel cycle cost estimation model and its cost estimation results for three nuclear fuel cycles using a dynamic model in Korea," Nuclear Engineering and Design, vol. 293, pp. 159-165, 2015.

[13] S. Choi, H. O. Nam, and W. I. Ko, "Environmental life cycle risk modeling of nuclear waste recycling systems," Energy, vol. 112, pp. 836-851, 2016.

[14] G. Zhang, D. Niu, Y. Shi et al., "Nuclear fuel cycle modelling using MESSAGE," Journal of Radioanalytical and Nuclear Chemistry, vol. 311, no. 2, pp. 1435-1440, 2017.

[15] F. Ganda, B. Dixon, E. Hoffman, T. K. Kim, T. Taiwo, and R. Wigeland, "Economic analysis of complex nuclear fuel cycles with NE-COST," Nuclear Technology, vol. 193, no. 2, pp. 219-233, 2016.

[16] R. Gao, S. Choi, W. Il Ko, and S. Kim, "Economic potential of fuel recycling options: a lifecycle cost analysis of future nuclear system transition in China," Energy Policy, vol. 101, pp. 526-536, 2017.

[17] S. Kim, H. Jang, R. Gao, C. Kim, Y. Chung, and S. Bang, "Break-even point analysis of sodium-cooled fast reactor capital investment cost comparing the direct disposal option and pyro-sodium-cooled fast reactor nuclear fuel cycle option in Korea," Sustainability, vol. 9, no. 9, 2017.

[18] S. Kim, W. Ko, H. Nam, C. Kim, Y. Chung, and S. Bang, "Statistical model for forecasting uranium prices to estimate the nuclear fuel cycle cost," Nuclear Engineering and Technology, vol. 49, no. 5, pp. 1063-1070, 2017.

[19] C. Zhou, X. Liu, Z. Gu, and Y. Wang, "Economic analysis of two nuclear fuel cycle options," Annals of Nuclear Energy, vol. 71, pp. 230-236, 2014.

[20] S. Brinton and M. Kazimi, "A nuclear fuel cycle system dynamic model for spent fuel storage options," Energy Conversion and Management, vol. 74, pp. 558-561, 2013.

[21] OECD/NEA, The Economics of the Back End of the Nuclear Fuel Cycle OECD/NEA, OECD/NEA, Issy-les-Moulineaux, France, 2013.

[22] G. D. Recktenwald and M. R. Deinert, "Cost probability analysis of reprocessing spent nuclear fuel in the US," Energy Economics, vol. 34, no. 6, pp. 1873-1881, 2012.

[23] W. I. Ko and F. Gao, "Economic analysis of different nuclear fuel cycle options," Science and Technology of Nuclear Installations, vol. 2012, Article ID 293467, 10 pages, 2012.

[24] B. H. Park, F. Gao, E.-H. Kwon, and W. I. Ko, "Comparative study of different nuclear fuel cycle options: quantitative analysis on material flow," Energy Policy, vol. 39, no. 11, pp. 6916-6924, 2011.

[25] G. D. Roo and J. E. Parsons, "Nuclear fuel recycling, the value of the separated transuranics and the levelized cost of electricity," 2009, https://dspace.mit.edu/bitstream/handle/1721. 1/51703/2009-\%2008.pdf? sequence $=1$ \&isAllowed $=y$.

[26] G. De Roo and J. E. Parsons, "A methodology for calculating the levelized cost of electricity in nuclear power systems with fuel recycling," Energy Economics, vol. 33, no. 5, pp. 826-839, 2011.
[27] M. V. Ramana and J. Y. Suchitra, "Costing plutonium: economics of reprocessing in India," International Journal of Global Energy Issues, vol. 27, no. 4, pp. 454-471, 2007.

[28] G. Aubert, L. Billes-Garabedian, and T. Barracco, Economic Assessment of Used Nuclear Fuel Management in the United States, Boston Consulting Group (BCG) for AREVA, Boston, MA, USA, 2006, https://imagesrc.bcg.com/Images/BCG_ Economic_Assessment_of_Used_Nuclear_Fuel_Managemen t_in_the_US_Jul_06_tcm9-132990.pdf.

[29] J. M. Charpin, B. Dessus, and R. Pellat, Economic Forecast Study of the Nuclear Power Option, Office of the Prime Minister of France, Paris, France, 2000, https://fire.pppl.gov/ eu_fr_fission_plan.pdf.

[30] OECD/NEA, The Economics of the Nuclear Fuel Cycle, OECD/ NEA, Issy-les-Moulineaux, France, 1994, https://www.oecdnea.org/upload/docs/application/pdf/2019-12/768-projectedcosts.pdf.

[31] P. Högselius, "Spent nuclear fuel policies in historical perspective: an international comparison," Energy Policy, vol. 37, no. 1, pp. 254-263, 2009.

[32] M. Bunn, J. P. Holdren, S. Fetter, and B. Van Der Zwaan, "The economics of reprocessing versus direct disposal of spent nuclear fuel," Nuclear Technology, vol. 150, no. 3, pp. 209-230, 2005.

[33] M. Schneider and Y. Marignac, "Spent nuclear fuel reprocessing in France," 2008, http://fissilematerials.org/library/ rr04.pdf.

[34] E. A. Schneider, M. R. Deinert, and K. B. Cady, "Cost analysis of the US spent nuclear fuel reprocessing facility," Energy Economics, vol. 31, no. 5, pp. 627-634, 2009.

[35] L. R. Penalonga and B. Y. M. Soria, "Analysis of the costs of spent nuclear fuel management in Spain: the Marino model," Energy, vol. 186, Article ID 115853, 2019.

[36] IAEA, Safety Glossary Terminology Used in Nuclear Safety and Radiation Protection, International Atomic Energy Agency, Vienna, Austria, 2018, https://www-pub.iaea.org/MTCD/ Publications/PDF/PUB1830_web.pdf.

[37] J. Bautista-Valhondo, L. Batet, and M. Mateo, "Minimizing the standard deviation of the thermal load in the spent nuclear fuel cask loading problem," Energies, vol. 13, no. 18, p. 4869, 2020.

[38] CFI, “Corporate Finance Institute," Net present value (NPV). https://corporatefinanceinstitute.com/resources/knowledge/ valuation/net-present-value-npv/.

[39] IAEA, Third National Report on Compliance with the Obligations of the Joint Convention on the Safety of Spent Fuel Management and on the Safety of Radioactive Waste Management, International Atomic Energy Agency, International Atomic Energy Agency, Vienna, Austria, 2017, https://www. iaea.org/sites/default/files/national_report_of_the_united_ar ab_emirates_for_the_6th_review_meeting_-_english.pdf.

[40] IAEA, "Management of spent fuel from nuclear power reactors learning from the past," in Enabling the Future- Proceedings of an International Conference, International Atomic Energy Agency, Vienna, Austria, 2019, https://www-pub.iaea. org/MTCD/Publications/PDF/P1905_web.pdf.

[41] KHNP, "Status of decommissioning preparation for kori \#1, nuclear safety \& security information conference, korea hydro and nuclear power," 2017, https://nucleus.iaea.org/sites/ connect/IDNpublic/IDN\%20Annual\%20Forum\%202017/SES SION\%205_KHNP\%20Status\%20of\%20Deccommissioning\% 20Preparation\%20for\%20Kori1_KIM.pdf.

[42] H. C. Sung, Y. B. Chang, C. Byung, and Y. L. Heung, "Operational experiences of on-site transport of spent nuclear fuels in Korea," in Proceedings of the Korea Institute of Nuclear 
Safety (KINS), 14th international symposium on the packaging and paper \# 073 transportation of radioactive materials, Berlin, Germany, September 2004.

[43] KHNP, "Spent fuel storage status in the third quarter. Korea hydro and nuclear power," 2020, https://npp.khnp.co.kr/ board/view.khnp?boardId=BBS_0000015\&menuCd=DOM_00 0000103004007000\&orderBy=REGISTER_DATE\%20DESC\&s tartPage $=1 \&$ dataSid $=3941$.

[44] J. Song, "Status and perspective of spent fuel management policy in Korea," 2017, http://www.nure.or.kr/download2? filename=2017_PT4.pdf\&filesource=2017_PT4.pdf.

[45] S.-H. Chung, C.-Y. Baeg, B.-Il. Choi, K.-H. Yang, and D.-K. Lee, "On-Site transport and storage of spent nuclear fuel at Kori NPP by KN-12 transport cask," Journal of Nuclear Fuel Cycle and Waste Technology, vol. 4, no. 1, pp. 51-58, 2006.

[46] EPRI, Rancho Seco Nuclear Generating Station Decommissioning Experience Report-Detailed Experiences, Electric Power Research Institute, Washington, D.C, USA, 2007, https://www.epri.com/research/products/1015121.

[47] M. Y. Jung, "The status of decommissioning engineering for kori1," kaif-jaif joint forum on nuclear power plant safety and decommissioning," 2018, https://doi.org/10.7733/jnfcwt.2019. 17.2.139.

[48] IAEA, Safety Considerations in the Transition from Operation to Decommissioning of Nuclear Facilities, International Atomic Energy Agency, Vienna, Austria,, 2004.

[49] IAEA, Country Nuclear Power Profiles- United States of America, International, Atomic Energy Agency, Vienna, Austria, 2020, https://cnpp.iaea.org/countryprofiles/Unite dStatesofAmerica/UnitedStatesofAmerica.htm.

[50] S. Maxwell, K. Chang-Lak, and K. David, "Consideration of spent fuel Pool Island as an interim management option of spent nuclear fuel for Kori unit 3 \& 4 during decommissioning of Kori site," Energy Strategy Reviews, vol. 21, pp. 163-171, 2018.

[51] H.-W. Seo, W. Sohn, and K.-H. Jo, "Proposal for the spent nuclear fuel management plan from the decommissioning of Kori site NPPs," Annals of Nuclear Energy, vol. 120, pp. 749-762, 2018.

[52] WNN, "Fuel-Loading-Under-Way-At-Shin-Kori-3," World Nuclear News. https://www.world-nuclear-news.org/Articles/ Fuel-loading-under-way-at-Shin-Kori-3.

[53] IAEA, Shin-Kori-3 Operational, Power Reactor Information System (PRIS), International Atomic Energy Agency, Vienna, Austria, https://pris.iaea.org/PRIS/CountryStatistics/Reactor Details.aspx? current $=885$.

[54] Testimony on the Nuclear Decommissioning of SONGS 2 \& 3 , Southern California Edison, Richland, WA, USA, 2014, https://www.sdge.com/sites/default/files/SCE-1_0_0.pdf.

[55] San Onofre Nuclear Generating Station Units 2 \& 3, Decommissioning Cost Estimate, The Kenrich Group LLC, 2017. http://www.anaheim.net/DocumentCenter/View/ 17403/SONGS-Decommissioning-Cost-Estimate?bidId=.

[56] C.-H. Cho, T.-M. Kim, K.-Y. Seong, H.-J. Kim, and J.-H. Yoon, "Cost comparisons of wet and dry interim storage facilities for PWR Spent nuclear fuel in Korea," Annals of Nuclear Energy, vol. 38, no. 5, pp. 976-981, 2011.

[57] TLG Services Inc, Decommissioning Cost Analysis for the MONTICELLO Nuclear Generating Plant, TLG Services Inc, Bridgewater, Connecticut, 2011.

[58] N. J. Aar Raboshaga, Tshangela, M. A. Atogo, D. S. Kessel, and L. C. Kim, Temporary Management of Spent Nuclear Fuel during Decommissioning of an NPP, Transactions of the
Korean Nuclear Society Autumn Meeting Gyeongju, Gyeongju, South Korea, 2016.

[59] MATHWORKS, “The MathWorks, Inc," MATLAB, Version R2021a. Natick, 2021.

[60] E. Solutions, "Decommissioning cost analysis of the san onofre nuclear generating station units 2\&3," 2014, http://www.globalchance.org/IMG/pdf/energysolutions2014songsdce_052114.pdf.

[61] R. P. Rechard, L. L. Price, E. Kalinina, and E. J. Bonano, "Managing spent nuclear fuel from generation to disposal: integration of the back-end of the nuclear fuel cycle," in Sandia National Laboratories AlbuquerqueIAEA International Conference on Management of Spent Fuel from $\mathrm{Nu}-$ clear Power Reactors, New Mexico, USA, 2015.

[62] APS, Consolidated Interim Storage of Commercial Spent Nuclear Fuel a Technical and Programmatic Assessment, Panel on Public Affairs, American Physical Society, Ridge, NY, USA, 2007, https://www.aps.org/policy/reports/popa-reports/upload/Ener gy-2007-Report-InterimStorage.pdf.

[63] S. R. Rod, Cost Estimates of Operating Onsite Spent Fuel Pools after Final Reactor Shutdown, Pacific Northwest Lab, Richland, WA, USA, 1991.

[64] EDISON, Testimony on the Nuclear Decommissioning of SONGS $2 \& 3$, an EDISON International Company, Rosemead, CA, USA, 2014.

[65] L. Eugene, W. Grant, I. Grant, and S. L. Richard, "Principles of engineering economy," 1982, https://www.worldcat.org/title/ principles-of-engineering-economy/oclc/32881464.

[66] M. Memorandum, Discount Rates for OMB Circular No. A-94 (Appendix C), Executive Office of the President, Office of Management and Budget, Washington DC, USA, 2021.

[67] US Inflation Rates, US Inflation Calculator, 20 December 2020, U.S Department of Commerce, New York, NY, USA, 2020, https://www.usinflationcalculator.com/inflation/currentinflation-rates.

[68] R. M. Cumberland, "Cost sensitivity analysis for consolidated interim storage of spent fuel: evaluating the effect of economic environment parameters," 2016. 